\title{
THE MEDIAL DIVISION OF THE MEDIAL GENICULATE BODY OF THE CAT: IMPLICATIONS FOR THALAMIC ORGANIZATION ${ }^{1}$
}

\author{
JEFFERY A. WINER ${ }^{*, 2}$ AND D. KENT MOREST $\ddagger$ \\ * Department of Physiology-Anatomy, University of California, Berkeley, California 94720 and $\ddagger$ Department of Anatomy, The \\ University of Connecticut Health Center, Farmington, Connecticut 06032
}

Received September 15, 1982; Revised July 29, 1983; Accepted August 2, 1983

\begin{abstract}
The structure of neurons and axons was studied in the medial division of the medial geniculate body of the cat with the Golgi methods. The results show that the medial division consists of morphologically heterogeneous neurons. The main types, in descending order of frequency, are medium-sized neurons with (1) radiate, (2) tufted, or (3) elongate dendrites; (4) small stellate or radiate neurons, including Golgi type II cells with a locally arborizing, sparsely branching axon collateral system; (5) large neurons, which are weakly tufted. A variety of afferent axons impose a reticulate appearance on the fiber architecture of the medial division. The dominant element in the neuropil consists of axons terminating in the medial division as well as a collateral system of fibers traveling to the adjacent ventral and dorsal divisions of the medial geniculate body. Four types of extrinsic axons are described, including two kinds of thin axons with collateral systems, thick fibers with restricted branches, and large axons with elaborate, serpentine collaterals.

Compared to the dorsal and ventral divisions of the medial geniculate body, where, respectively, radiate and tufted neurons are more frequent, the medial division is intermediate in a sense-not that the degree of radiate or tufted dendritic branching is less well developed, but neither type of cell predominates. Moreover, all of the cell types are overlapping in distribution, although the large ones tend to be more common rostrally in the medial division. Likewise, there is no clear-cut regional segregation of axonal types. The ascending projections to the medial division originate in many different structures, involving purely auditory tracts from the inferior colliculus, spinal inputs, and pathways from polysensory regions, such as the midbrain tegmentum and deep layers of the superior colliculus. The spinothalamic tract projects most heavily to the rostromedial region of the medial division bordering the ventrobasal complex. The auditory input from the central nucleus of the inferior colliculus tends to project more heavily to the caudolateral region next to the ventral nucleus of the medial geniculate body. However, these inputs overlap in the medial division. Moreover, the pathways from the tegmentum and the superior colliculus have a broad distribution in the medial division. Still other inputs are known, not to mention those from the cerebral cortex and a widespread and complicated pattern of thalamocortical projections.

The morphological heterogeneity of medial division neurons and axons is consistent with the large number and functional diversity of ascending and descending connections, involving different sensory systems, including auditory and somatic sensory pathways. These findings suggest that the medial division is morphologically specialized for processing parallel and partially overlapping channels in the analysis of somatic, acoustic, and possibly other sensory inputs. To some extent, different types of neurons could mediate separate inputs and outputs. But there are more different connections than neural types, as presently defined. Therefore, certain types of neurons, if not individual cells, may process more than one kind of input. Moreover, the different afferent inputs are not all uniformly distributed. Consequently, some of the neurons near the ventrobasal complex would be more strongly aligned with the somatic sensory pathway, whereas others near the ventral nucleus of the medial geniculate body would be more closely aligned with the auditory system. Thus some neurons or groups of neurons could provide for parallel processing, others for convergence.
\end{abstract}

\footnotetext{
1 This research was supported by United States Public Health Service Grants 5 R01 NS14347 to D. K. M. and 1 F32 NS05485 and 1 R01 NS16832 to J. A. W., and by University of California Faculty Research Grants to J. A. W. We gratefully acknowledge the expert assistance of
}

S. D'Amato, L. Andrus, and C. Bellue. A preliminary report of these findings has appeared (Winer, 1979).

${ }^{2}$ To whom correspondence should be addressed at the University of California. 
Neuroanatomical studies show that the medial division of the medial geniculate body contains the same general types of neurons as do the neighboring main sensory nuclei of the thalamus, namely, the tufted neurons and small Golgi type II cells of the ventral nucleus of the medial geniculate and ventrobasal complex, and also the same general type of radiate neurons as the neighboring regions of the dorsal division of the medial geniculate body and the association nuclei of the posterolateral thalamus, namely, the pulvinar-lateral posterior-suprageniculate complex. Study of the neuronal morphology of this region, considered together with its connections and electrophysiological properties, suggests the following concept of the structural organization of the posterolateral thalamus. The main sensory nuclei, i.e., the ventral nucleus of the medial geniculate body, the dorsal nucleus of the lateral geniculate body, and the ventroposterior nuclei of the ventrobasal complex, have a neuronal architecture dominated by bushy principal neurons with tufted dendrites, small Golgi type II cells, synaptic nests, and physiological properties characterized by a high degree of synaptic security, modality specificity, and topographic organization. Between these nuclei are certain groups of neurons in the medial division of the medial geniculate body, in parts of the lateral geniculate bociy, and in the pulvinar-lateral posterior-dorsal nuclear complex, namely, the associated sensory complex, in which stellate principal neurons play a more dominant role and there is a higher degree of sensory convergence and a lesser degree of synaptic security. The associated sensory complex consists of the aligned cell groups, which are associated more or less with one of the main sensory nuclei and its sensory modality, and the unaligned cell groups, including polysensory ones, which would be less securely tied to one sensory modality.

The medial division is one of the three main parts of the medial geniculate body of the cat (Rose and Woolsey, 1949a; Morest, 1964). The separate status of the medial division and the uniqueness of its magnocellular neurons (so-called "pars magnocellularis") are well recognized (Ramón y Cajal, 1911; Rioch, 1929). It is composed of cytologically diverse neurons, situated among the fibers of the brachium of the inferior colliculus caudally, while the large neurons are conspicuous rostrally, wedged between the ventrobasal complex and the other medial geniculate divisions.

The medial division has been implicated in a variety of sensory functions and a multiplicity of connections (see Erulkar, 1975). Because of this complexity, it is difficult to integrate information about this region in a general scheme of thalamic function. Perhaps one reason for this is that the medial division comprises several diverse groups of cells. Further progress requires a con-

\footnotetext{
${ }^{3}$ The abbreviations used in the figures are: $A q$, cerebral aqueduct; $B I C$, brachium of inferior colliculus; $B I C d$, dorsal accessory nucleus of $\mathrm{BIC} ; B I C i$, interstitial nucleus of $\mathrm{BIC} ; B I C v$, ventral accessory nucleus of BIC; $B S C$, brachium of superior colliculus; $C G L$, lateral geniculate body; CGM, medial geniculate body; $C G M d$, dorsal division of CGM; $C G M m$, medial division of CGM; CGMv, ventral division of CGM; $C P$, cerebral peduncle; $D$, dorsal nucleus of CGMd; $D D$, deep dorsal nucleus of CGMd; $D S$, superficial dorsal nucleus of CGMd; $G$, glial cells; $G L$, lateral geniculate complex; $G L d$, dorsal nucleus of $G L ; L$, posterior limitans nucleus; $L M N$, lateral mesencephalic nucleus; $L P$, lateral posterior nucleus; $M$, medial division of CGM; $M B$, mammillary bodies; $M L$, medial lemniscus; $M R F$, mesencephalic reticular formation; $O T$, optic tract; $O V$, pars ovoidea of CGMv; $P T$, pretectum; $P U L$, pulvinar; $R N$, red nucleus; $S C$, superior colliculus; $S G$, suprageniculate nucleus of CGMd; $S N$, substantia nigra; $S P$, suprapeduncular nucleus; $S P N$, subparafascicular nucleus, caudolateral extension; $V$, ventral nucleus of CGMv; $V L$, ventrolateral nucleus of CGMv; $V P L$, ventroposterolateral nucleus; $V P M$, ventroposteromedial nucleus. Planes of section are: $A$, anterior; $D$, dorsal; $L$, lateral; $M$, medial; $P$, posterior; $V$, ventral.
}

siderably more developed anatomy than is currently available.

The goal of this report is to open the way for future studies dealing with the functional neuroanatomy of this region. We describe here the neuronal architecture of the medial division, the structure of the common cell types, the neuropil and fiber architecture, the common varieties of axonal endings in the medial division, and their presumptive targets.

These observations are compared to analogous structures of the main sensory and associated pathways in the medial geniculate body and adjacent regions of the thalamus. These comparisons have implications for a general view of the anatomical organization of the thalamic sensory nuclei in relation to their brainstem and cortical projections.

\section{Materials and Methods}

The techniques and material used in this study are similar to those from parallel studies of the neurons and axons of the dorsal division of the medial geniculate body (Winer and Morest, 1978; 1983 a, b). A complete account of the technical details is available (Morest and Morest, 1966; Morest, 1981). Briefly, cats 3 months or less in age were prepared for rapid Golgi impregnations; older material, including adults, was usually impregnated with the Golgi-Cox method but also with rapid Golgi methods. About 150 brainstems were prepared and supplemented by Protargol-, Weil-, or Weigert-stained serial sections from other experiments. We have taken pains to ensure that the critical observations apply to the mature state, unless otherwise noted (Morest, 1964, 1969, 1975a). Drawings were rendered with a drawing apparatus and plan- or semi-apochromatic objectives with long working distance. All of the critical observations of cellular details, such as dendritic appendages and axonal endings, 

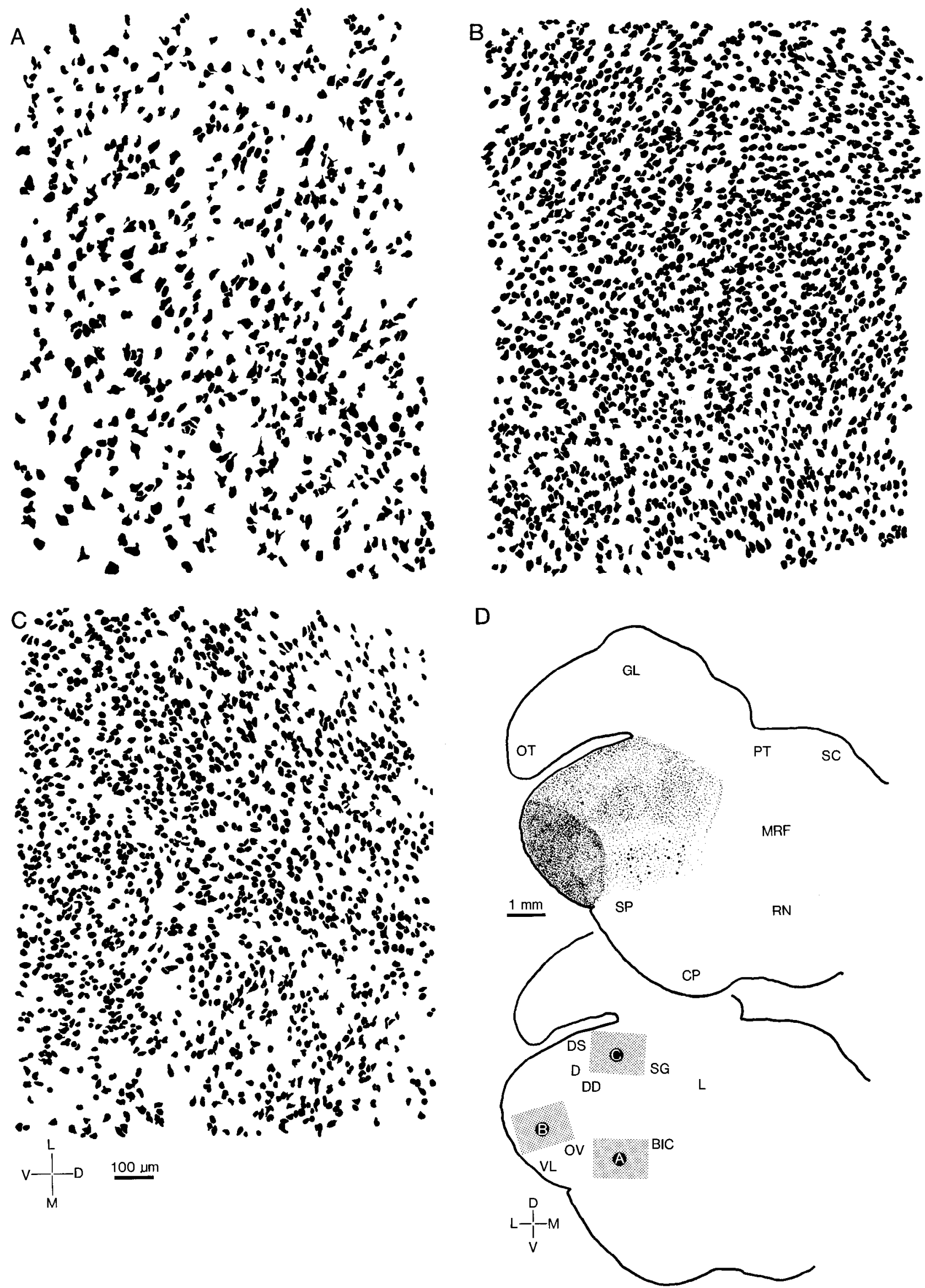

Figure $1 .^{3}$ Medial geniculate body cytoarchitecture. $A$, Neurons of the medial division. $B$, Neurons of the ventral division. $C$, Neurons of the dorsal division. Thionin-stained, $50-\mu \mathrm{m}$ thick, celloidin-embedded transverse section. Planachromat, $\times 16, \mathrm{~N} . \mathrm{A}$. 0.35. $D$, Low power view of areas from which $A, B$, and $C$ came. Planachromat, $\times 4$, N.A. 0.13 . Adult cat. 
were studied in rapid Golgi preparations with oil-immersion lenses.

\section{Results}

The medial division of the medial geniculate body is intercalated between the dorsal division, dorsally, the ventral division, laterally, the mescencephalic reticular formation and medial lemniscus, medially, and the suprapeduncular nucleus, ventrally (Fig. $1 D$ ). At its midpoint the medial geniculate body reaches its largest dimensions, and each subdivision is present. At the level of the oculomotor nerve root, the neurons of the medial division infiltrate among the fibers of the brachium of the inferior colliculus and fuse with its interstitial nucleus.

In Nissl-stained material midway through the medial geniculate body, the medial division is conspicuous (Fig. $1 A)$. Its neurons include some larger in diameter and more variable in size than those of the ventral (Fig. $1 B$ ) and dorsal (Fig. 1C) divisions. The medial division is dappled by islands of cells irregularly dispersed among fiber zones up to $100 \mu \mathrm{m}$ or more in diameter. These cellpoor zones correspond to large masses of fibers visible in Bodian, Weil, and rapid Golgi preparations. Some of these fibers contribute to the terminal plexus of the medial division, but many pass on to the ventral and dorsal divisions, while some emit preterminal collaterals de passage.

\section{Neuronal architecture}

Since the validity and accuracy of these descriptions depend upon the confidence with which they can be ascribed to the medial division, the criteria for identifying it will be briefly summarized. The relatively low cellular density and reticulated appearance of the neuropil have already been noted. In addition, the structure of medial division neurons is distinct from that of neurons in the midbrain reticular formation and all other parts of the medial geniculate body. Finally, the morphology of individual axons within the medial division, both intrinsic and extrinsic, is unique.

The Nissl preparations suggest that the medial division is a congeries of cell types. Golgi-impregnated material reveals a variety of neurons. Besides differences in size, these neurons vary also in the shapc of their dendrites. Thus, some cells have a large soma and radiate dendrites with Y-shaped branches (Fig. 2, 1), whereas other, very large neurons have tufted (Fig. 2,3 ) or discshaped (Fig. 2, 8) dendritic fields. These magnocellular neurons are the most striking, but numerically the least common cells in the medial division.

The most common neurons in the medial division are medium-sized, multipolar cells with a round or oblate perikaryon about $25 \times 35 \mu \mathrm{m}$ in diameter (Fig. 2, 5, 6, 10 , and 21). These neurons are conspicuous in Nissl (Fig.
$1 \mathrm{~A}$ ), Golgi-Cox (Fig. 2, 2, 4, 7, 9, and 12), and rapid Golgi (Fig. 3) preparations. Their dendritic fields may be disc shaped (Fig. 2, 15), spherical (Fig. 2, 1), or intermediate to these categories (Fig. 2, 13). Less common are the small neurons with sparse, limited dendrites (Fig. 2, 11, 20,22 , and 27).

In Golgi preparations two general categories of principal neurons can be distinguished on the basis of the configuration of the dendrites and their branching patterns-bushy cells and stellate cells. Bushy cells are characterized by tufted dendrites, whose branches resemble sheaves of wheat or brooms, which produce the overall impression of a bush or clumps of bushes (Fig. 3, lower left). The fundamental branching pattern consists of groups of second-order branches arising in the same parts of the dendritic field. Stellate cells have star-shaped dendritic fields, more or less irregular in outline, in which the dendrites tend to diverge or radiate (Fig. 3, upper center). The stellate configuration results from the basic radiate branching pattern, which is characterized by a tendency of the second- and higher-order dendrites to bifurcate dichotomously into consecutive daughter branches. It is possible to distinguish more or less degrees to which the radiate or tufted branching patterns are expressed. Thus, gradations of more or less bushy or stellate cells can be identified. Thus, in the medial geniculate body, the most extremely tufted bushy cells occur in the ventral nucleus, and the most strongly radiate dendrites of stellate cells are in the posterior limitans nucleus, whereas most of the stellate neurons throughout the medial and dorsal divisions have only moderately radiate dendritic branching patterns or, in some cases, patterns intermediate to the radiate and tufted extremes. However, each variety of principal neuron, whether radiate or tufted, is isotypic and has a characteristic distribution with respect to the medial division. A further discussion of these definitions appears elsewhere (see Ramon-Moliner, 1962; Morest, 1964; Winer and Morest, 1983a; D. K. Morest and J. A. Winer, submitted for publication). A description of the structure of each type of neuron follows in which cells are classified on the basis of medium, large, and small somata and further characterized on the basis of dendritic configuration.

The medium-sized stellate neuron (Fig. 3, upper center and lower right) is common in the medial division. Its predominantly smooth soma has as many as six to eight thick main branches, each of which usually bifurcates twice in wide-angled, oblique shapes. Some dendrites have massive trunks whose finer terminal parts are parallel to one another and to the plexus formed by axons from the brachium of the inferior colliculus. Most dendrites run at right angles, rather than parallel to the long axis of fibers from the brachium of the inferior colliculus. The dendritic branching pattern of this cell is less radiate than that of the analogous neurons of the dorsal division,

Figure 2. A montage of neurons from four consecutive $100-\mu \mathrm{m}$-thick sections through the central part of the medial division. Medium-sized multipolar cells predominate $(5,7,10,12$, and 21); many have disc-shaped (14 and 15) or bushy (4 and 28) dendrites. Magnocellular $(1,3,8,13,17$, and 23 to 26$)$ elongate (18), and Golgi type II $(11,16,20,22$, and 27) neurons are present. Planachromat, $\times 16$, N.A. 0.35 . Adult cat, Golgi-Cox method. In this and the following figures, where an axon or dendrite is transected is indicated by a circular profile. 


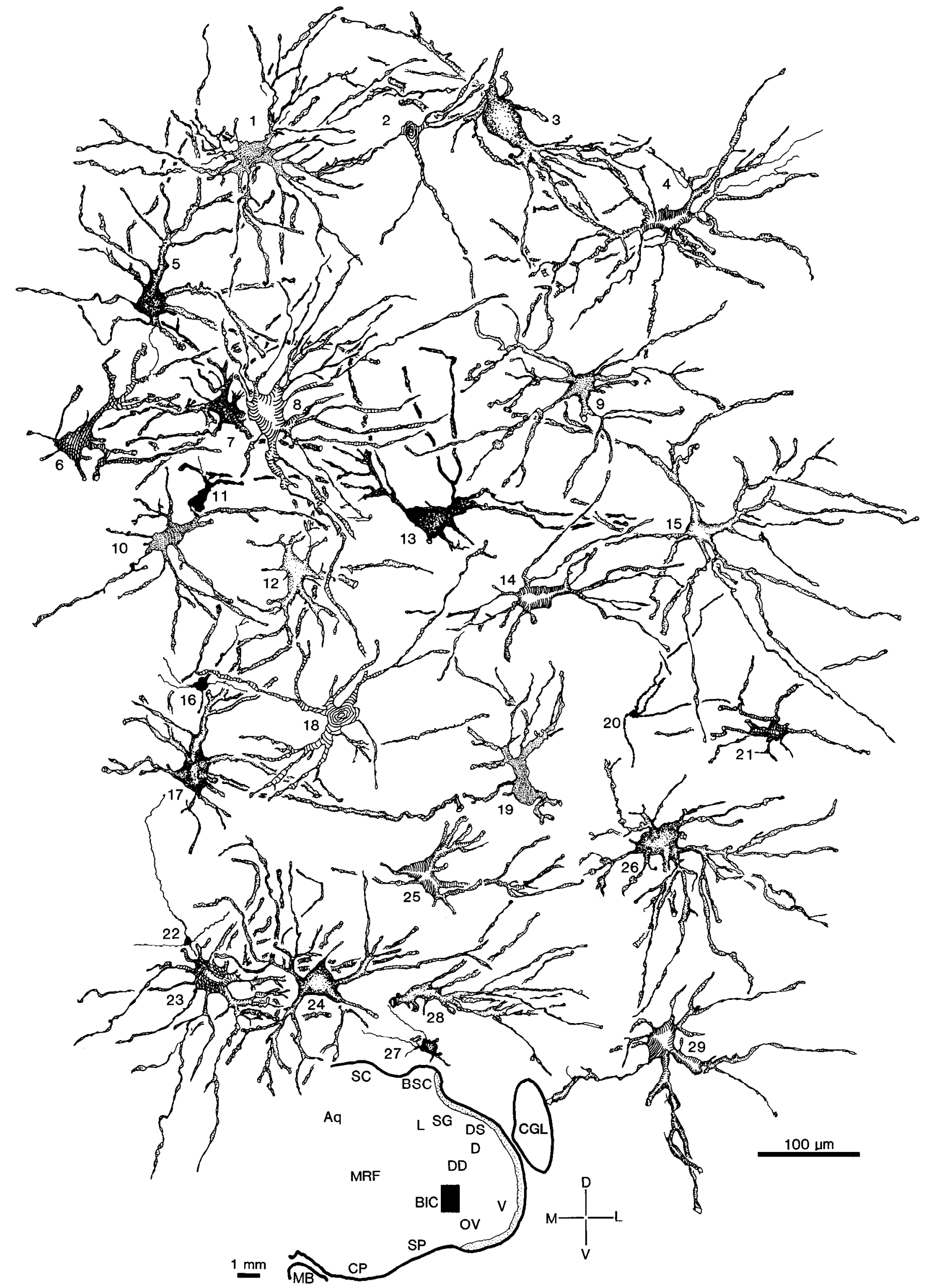

Figure 2 


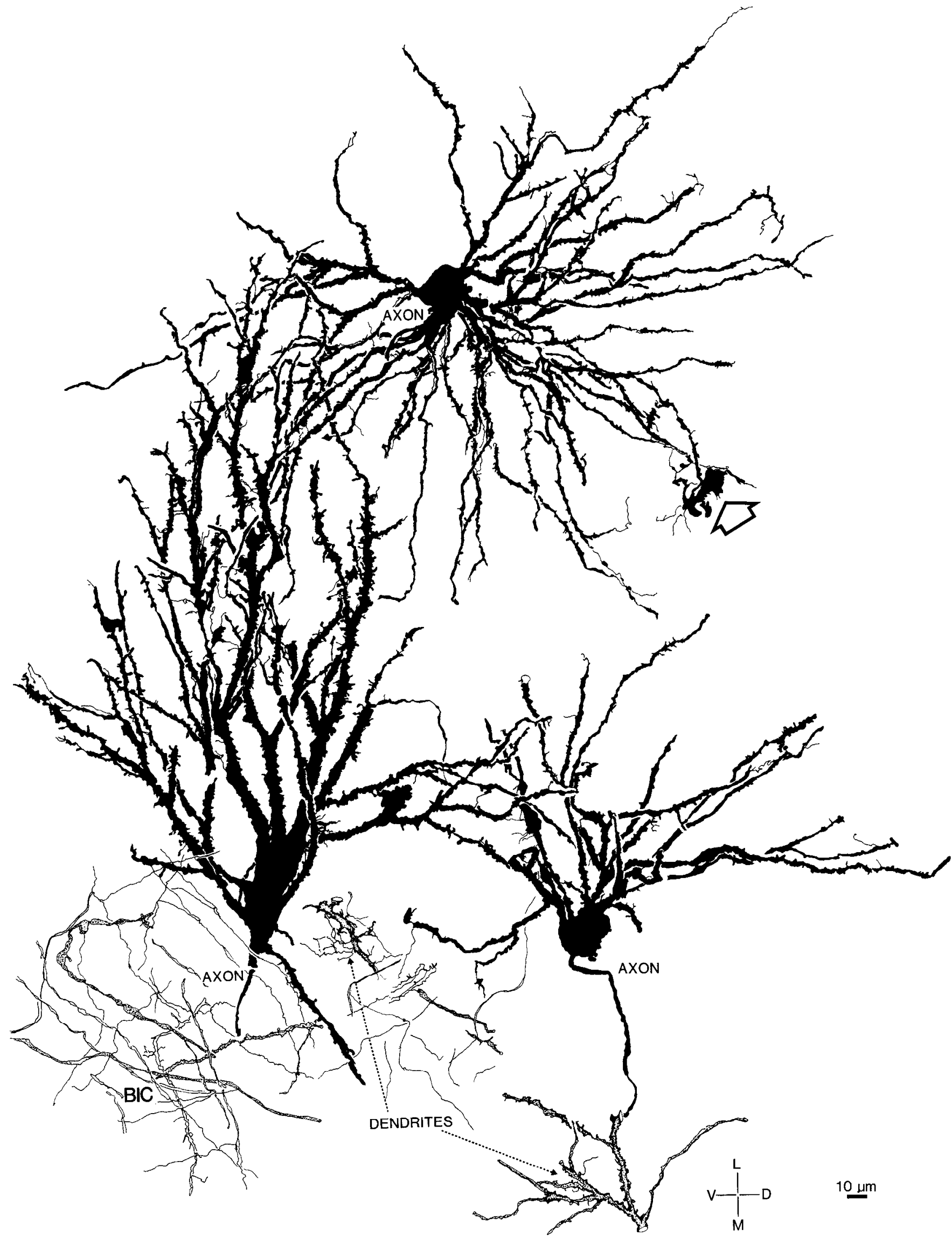

Figure 3. Medium-sized stellate and bushy principal neurons adjacent to inferior brachial fibers. The stellate cell in the upper center of the field has a spheroidal dendritic field, the one at the lower right has the shape of a cone with its base in an orthogonal plane. Lower left, Bushy cell with fine and coarse afferents. Open arrowhead, dendritic growth cone. Planachromat, $\times 40$, N.A. 0.75 . Twenty-five-day-old cat, rapid Golgi method. 
and the dendritic domain occupies a field of $250 \times 300$ $\mu \mathrm{m}$. Appreciable areas of the soma do not give rise to any dendrites or have only small, poorly developed ones. Each dendrite has a variety of appendages. Short, thorn-like spines are numerous and usually less than $5 \mu \mathrm{m}$ long, except for the long filiform variety, which may be up to $20 \mu \mathrm{m}$ long, at least in immature animals. Squat and stumpy appendages arc common, whereas longer, pedunculated ones, like those in the dorsal division, are unusual. A striking feature of these dendrites is their tendency to be spiny in places. Long segments may be virtually spine free, whereas the next few micrometers may be heavily covered. The axon of the medium-sized stellate neuron is 2 to $3 \mu \mathrm{m}$ thick, emerges from the soma or a proximal dendrite, and, insofar as it can be visualized in rapid Golgi preparations, is devoid of extensive collaterals. These neurons are especially common in the caudal half of the medial division.

The medium-sized tufted cell (Fig. 3, lower left) differs from the stellate cell in several ways. Its soma is usually elongated and sometimes nearly rectangular, measuring some $20 \times 40 \mu \mathrm{m}$ in both Nissl and Golgi preparations. Its dendritic field differs in size, shape, and orientation. The tufted dendrites are often shorter and form cylindrical, restricted arrays, which appear largely, although not completely, confined to narrow venues in the neuropil, in contrast to stellate cells. Bushy cell dendrites are also thicker and appear to have more spines than do those of stellate cells. Finally, almost the entire dendritic domain of this cell is parallel to the brachial axons and largely orthogonal to cortical axons (Fig. 3, lower left). The bushy cell dendrites frequently divide at or near their ends and usually have 6 to 10 branches. Primary branches are often very thick $(10 \mu \mathrm{m}$ or more). The spine-free zones are also seen, as in stellate cells. The axon of this cell is about $2 \mu \mathrm{m}$ thick, lacks collaterals, and often parallels the brachial fibers for some distance, then turns rostrally and dorsally toward the auditory radiation. The dendrites of adjacent neurons (including Golgi type II cells) often commingle in complex and gnarled patterns among small clusters of medial division neurons. Bushy neurons occur more often rostrally.

The medium-sized elongate neuron has an elongated dendritic field, on the order of $200 \times 400 \mu \mathrm{m}$ (Fig. 2, 18; Fig. 4). It is basically a variety of stellate cell with a distinctly radiating branching pattern of dendrites occupying a cylindrical or pinecoid field. The $25 \times 30$ to 35 $\mu \mathrm{m}$ soma is smooth and slightly elongated. From it emerge five to nine dendrites, usually less than $5 \mu \mathrm{m}$ thick. Passing oblique to the cardinal planes, these branch two to four times and often divide into delicate terminal twigs (Fig. 4, lower panel), which often form parallel, curved arrays, winding about one another for several hundred micrometers. The spine-bearing portions of elongate cell dendrites have fewer and less variable appendages, which are thinner and more delicate than those of either the tufted or radiate cells. The serpentine and intertwined dendritic segments nearly always parallel the brachial axons, but the isolated single dendrites may not.

The magnocellular neuron (Fig. 2, 3, 13, 17, and 23 to 26 ; Fig. 5) has the largest cell body in the medial division. Although more frequently encountered in the rostral half, nevertheless it is probably the least common cell type in the medial division. It has a $35 \times 40 \mu \mathrm{m}$ or larger perikaryon with up to 10 major dendrites, which branch generally in a tufted pattern. This branching pattern is not as highly tufted as in the ventral nucleus. The terminal dendrites usually continue obliquely as slender tapering shafts capped with dentate or pedunculated endings or clasp-like profiles. For the size of the cell the dendrites are quite slender ( 3 to $4 \mu \mathrm{m}$ ) compared with those of medium-sized bushy cells. The few spines usually cluster at irregular intervals and include most of the varieties seen on other neurons of the medial division. The longest spines are less than $5 \mu \mathrm{m}$ long (Fig. 5). Often the distal dendrites of magnocellular neurons intertwine like those of elongate cells (Fig. 4), but not as much as those of bushy neurons (Fig. 3, lower left). Their apical and basal dendritic shafts pass at right angles to the brachial axons, whereas the intermediate dendrites parallel them. The axon of this cell is 2 to $3 \mu \mathrm{m}$ thick and emerges from the trunk of a dendrite or, less often, from the cell body. This axon does not appear to form local collaterals in its course toward the auditory radiation.

Local circuit neurons (Golgi type II cells) (Fig. 2, 11, 16, 20, and 27; Fig. 6) of the medial division are less common than stellate, bushy, or elongate principal cells but somewhat more frequent than magnocellular neurons. The basis for classifying such cells has been discussed elsewhere (Morest, 1965a, c; Winer and Morest, 1983a). The soma, $15 \times 20$ to $25 \mu \mathrm{m}$ in diameter, is often triangular in shape with a few surface irregularities. Four to six large dendrites usually divide once or twice in a disc-shaped or flattened field, some $250 \mu \mathrm{m}$ or less in diameter. The long axis of the dendritic field is parallel to the brachial axons. The dendrites have broad Yshaped, or nearly T-shaped, bifurcations and long tapering ends less than $1 \mu \mathrm{m}$ in diameter (Fig. $6 B$ ).

The shafts of these dendrites are either smooth for long distances (up to $100 \mu \mathrm{m}$ ) or have a variety of varicosities and appendages, which are especially prominent on the distal segments (Fig. 6B). These form long, slender filopodia capped with dilations (Fig. $6 B, 1$ ) or Yshaped segments; short, thin spines (Fig. $6 B, 4$ ), with or without short pedunculated branchlets; short, thick spines (Fig. $6 B, 2$ ); long, digitiform ones without caps or branches and having either a straight or curved course (Fig. 6B, 3); and long, complex, and irregular appendages that may recurve or wind about the shaft of other appendages (Fig. 6B, 5). These long, stringy branchlets are particularly numerous on the distal dendrites. Unusual varieties, including appendages with bifurcations, also occur (Fig. 6B,6), as well as spines with large terminal expansions (Fig. $6 B, 7$ ).

The axon of this cell type, unlike that of the others, has a collateral network and often appears to be confined to the medial division (Fig. 6A). After emerging from a proximal dendrite, the $2-\mu \mathrm{m}$-thick axon typically divides into progressively thinner, Y-shaped branches. One part of the collateral network is recurrent to the cell's dendrites, whereas other segments project as fine processes to the adjacent neuropil. The distal branches of these processes are often very thin (less than $0.5 \mu \mathrm{m}$ ). No more than 10 collaterals have been seen and usually far less; however, in single sections, these cannot be traced to 


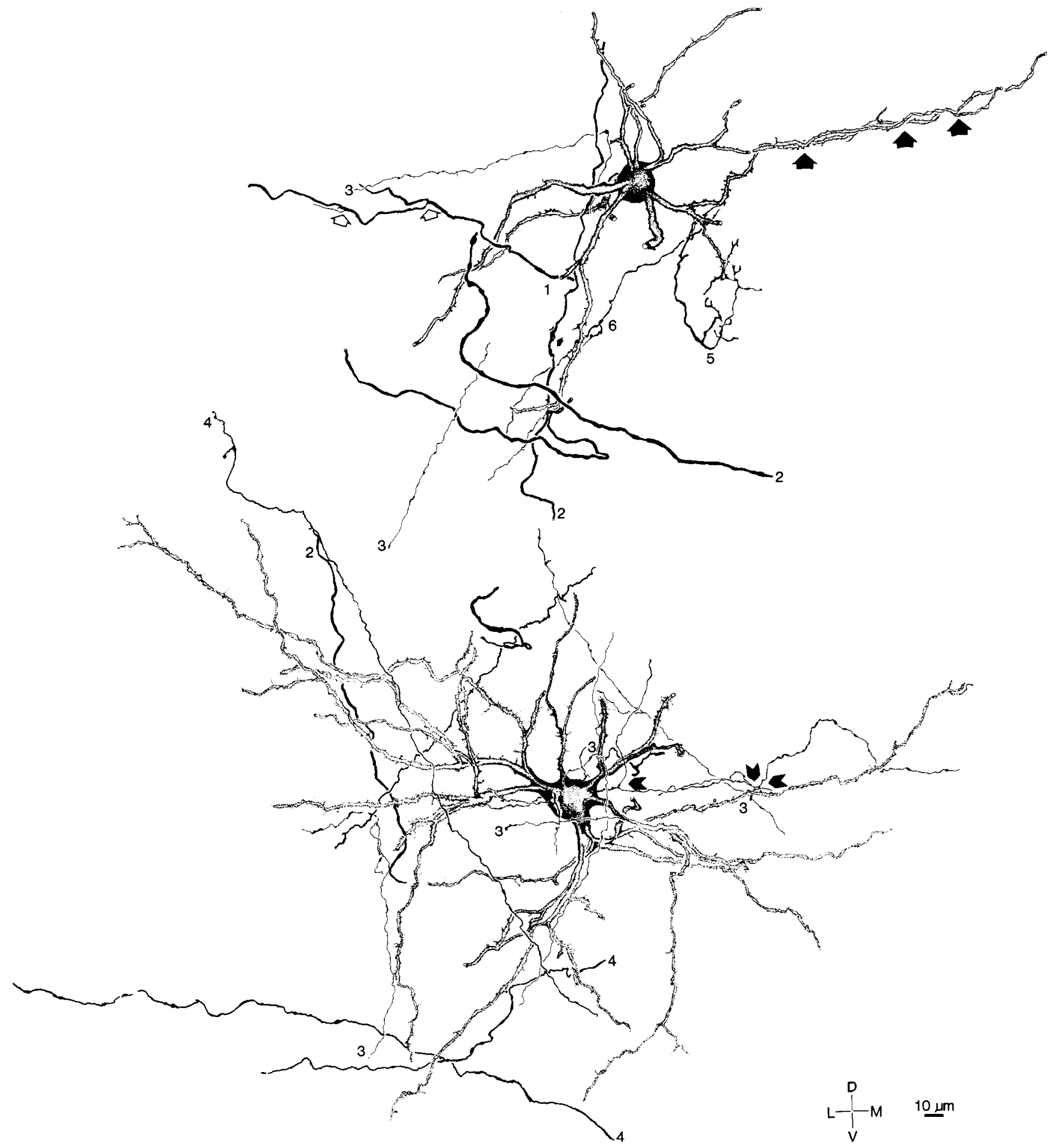

Figure 4. Two elongate neurons and portions of the axonal plexus from adjacent sections. The distal dendrites often parallel each other (large solid arrowheads). 1, Thick, type IV axon; 2, principal cell axons; 3, type II axons; 4, type I axons; 5 , type III axon forming a terminal basket, which may be perisomatic ( $c f$. Fig. 5, 2); 6, sinuous axon. Arrowtails, peridendritic terminal branches of type II axons; hollow arrowheads, branch points of type IV axon; small arrowhead, axonal excrescences. Semiapochromat, $\times 100$, N.A. 1.25. Twenty-nine-day-old cat, rapid Golgi method.

their ends in many instances. Although these axons make a significant contribution to the neuropil, they do not strongly color its texture, as the corresponding cell type tends to do in the dorsal division.

\section{Axonal structure}

The neuropil of the medial division has a characteristic texture, which is dominated by the fascicles of brachial 
axons (Fig. 8). On leaving the brachium, the axons turn laterally and cross the medial division either to terminate or to form collaterals within it or to pass more laterally. Medially, the axons impart a striated appearance to the neuropil (Fig. 8, lower left). The corresponding cell-poor zones of the background are apparent in Nissl preparations (Fig. $1 A$ ). There is a distinct change in the neuropil at the boundaries of adjacent subdivisions in the medial

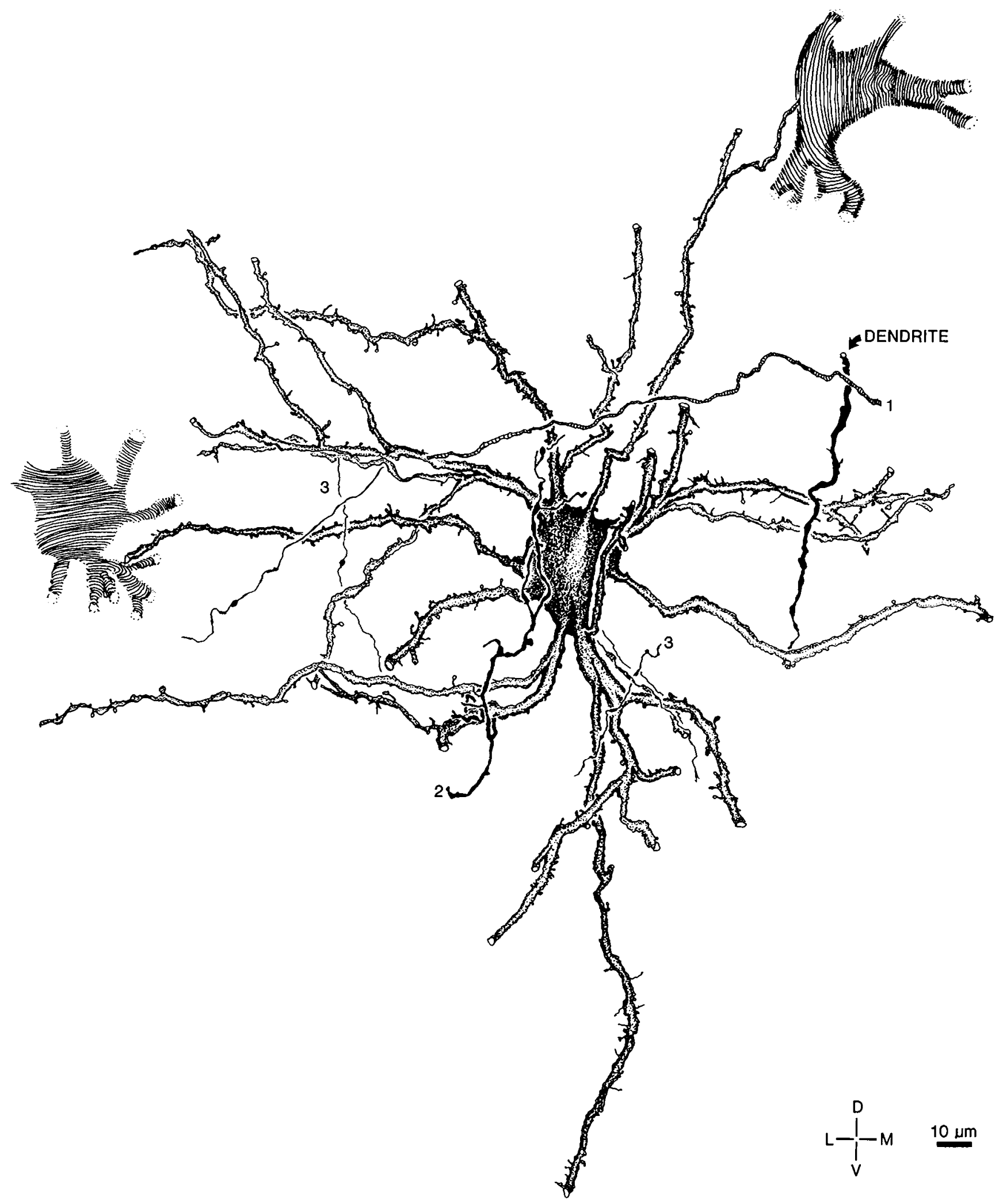

Figure 5. Magnocellular neurons. Note the perisomatic terminal of a type III axon (2) and the intermingling of other magnocellular neurons (striped profiles) and a dendrite. 1, Intermediate-sized brachial axon; 3, slender, beaded, probably descending type I axons. Semi-apochromat, $\times 100$, N.A. 1.25. Twenty-nine-day-old cat, rapid Golgi method. 


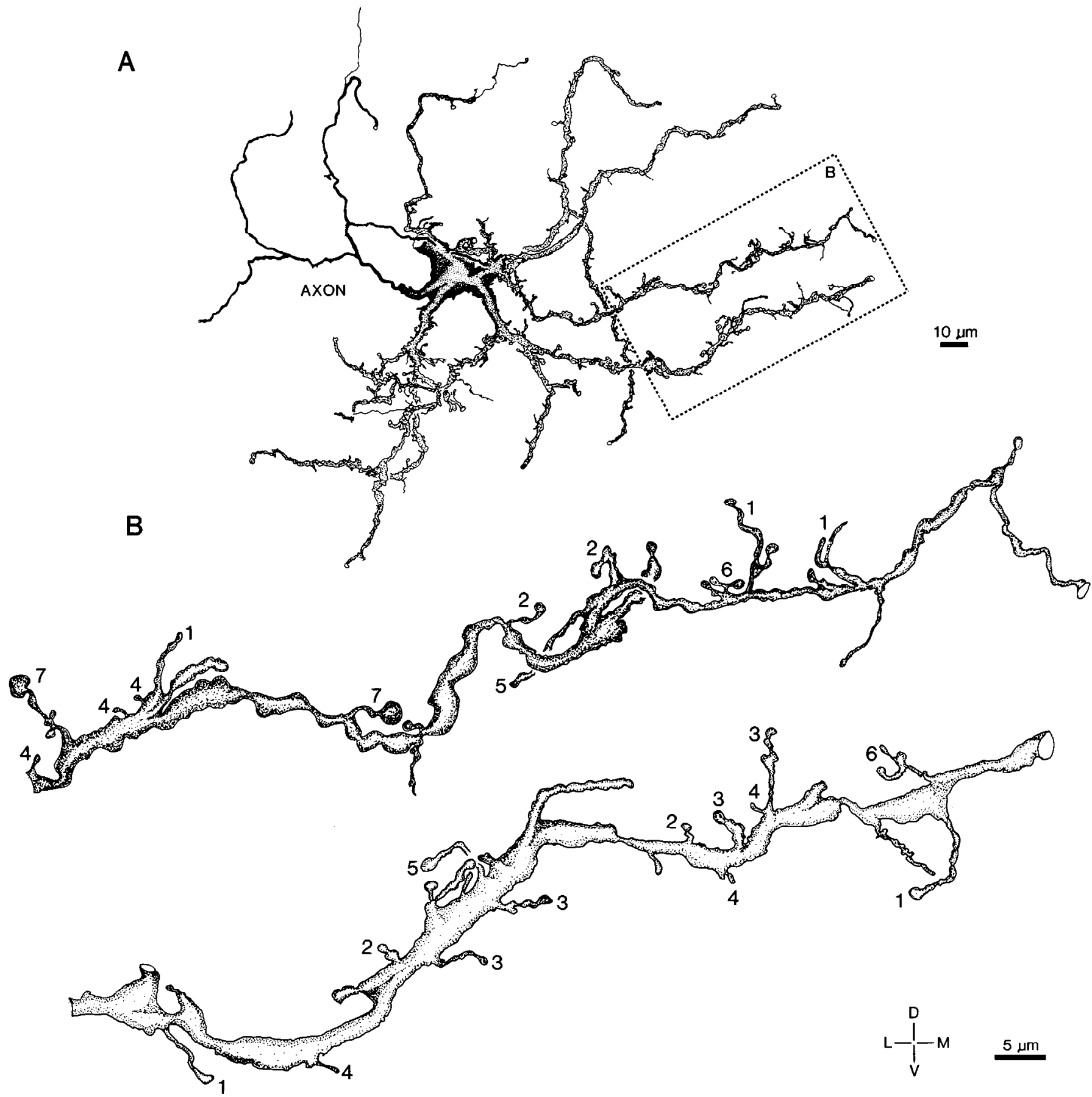

Figure 6. A, Stellate Golgi type II cell. B, Many varieties of dendritic spines (1 to 7). Planapochromat, $\times 100$, N.A. 1.32. Twenty-three-day-old cat, rapid Golgi method.

geniculate body, which reflects the contributions of Golgi type II axons and other fine fibers (e.g., Fig. 8, $D D$ ). Although most axons in the medial division move in a ventrolateral-to-dorsomedial axis, other fibers pass orthogonal to these. The latter are probably of cortical (Diamond et al., 1969) or lateral tegmental (Morest, $1965 \mathrm{~b}$ ) origin and also include axons of principal cells coursing to the auditory radiation.

\section{Axonal endings}

The axon terminals in the medial division seem more diverse than their preterminal portions indicate.
Whereas the majority of brachial axons are thick or thin with bulbous swellings, smooth axons of both sizes also occur (Fig. 8). The following account describes the most common axon types but is by no means exhaustive.

Slender axons (type I), about $1 \mu \mathrm{m}$ thick, and traveling in the brachium of the inferior colliculus, frequently gather near the dendrites of medial division neurons (Fig. 3 , lower left). These axons, which may be beaded (Fig. 4, 4 , lower left) or have small pedunculated appendages (Fig. $7 B$, lower right), often travel along principal cell dendrites making serial contacts or dense peridendritic nests on both spines and shafts. Extremely slender axons 


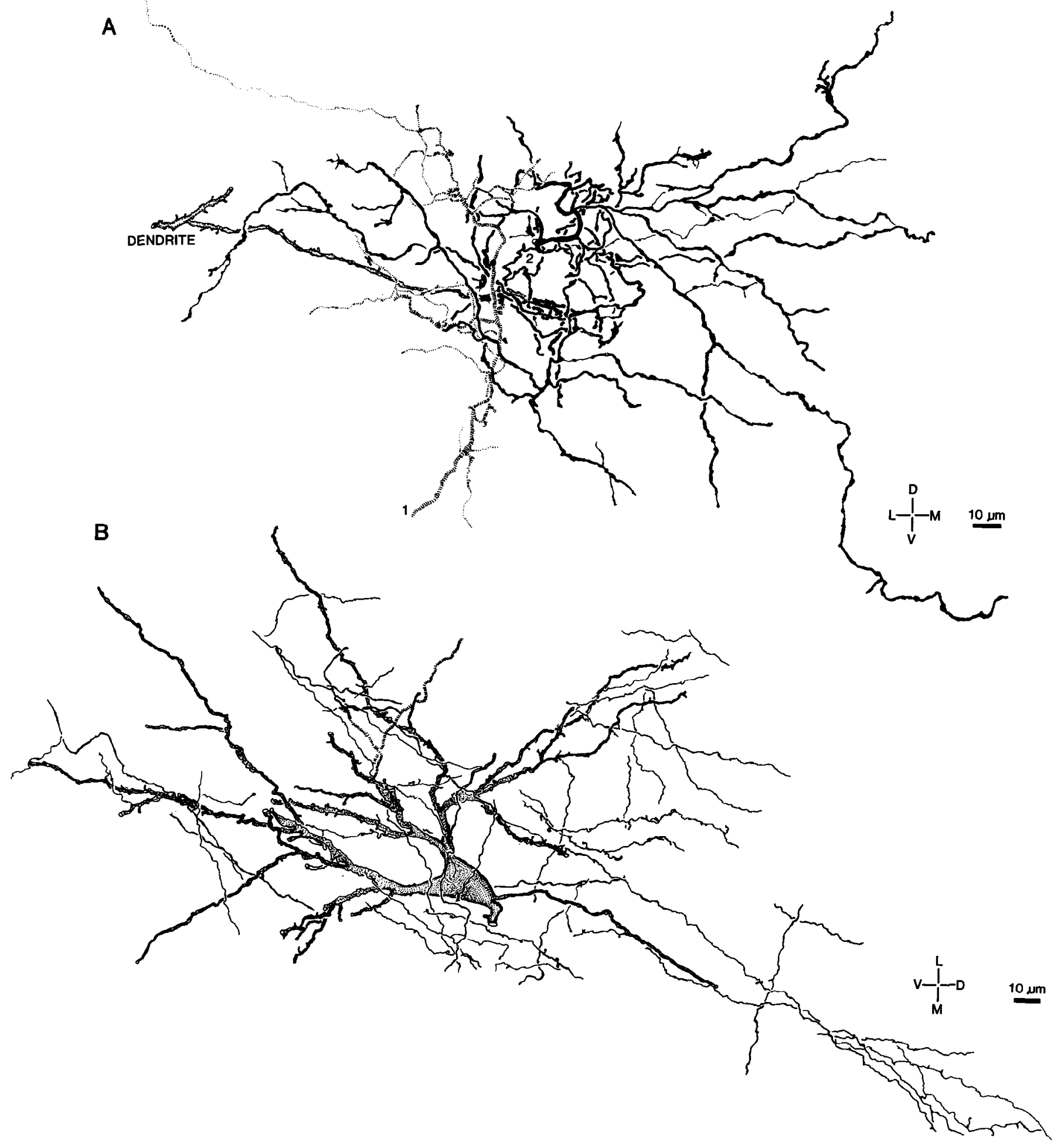

Figure 7. Varieties of axonal endings. A, Two large, type IV axons ( 1 and 2) arborize about each other and the dendrite of a principal cell. Planapochromat, $\times 100$, N.A. 1.32 . Forty-four-day-old cat, rapid Golgi method. $B$, The peridendritic and perisomatic collaterals of type I and II axons near an elongate cell. Planapochromat, $\times 100$, N.A. 1.32. Thirty-six-day-old cat, rapid Golgi method. 


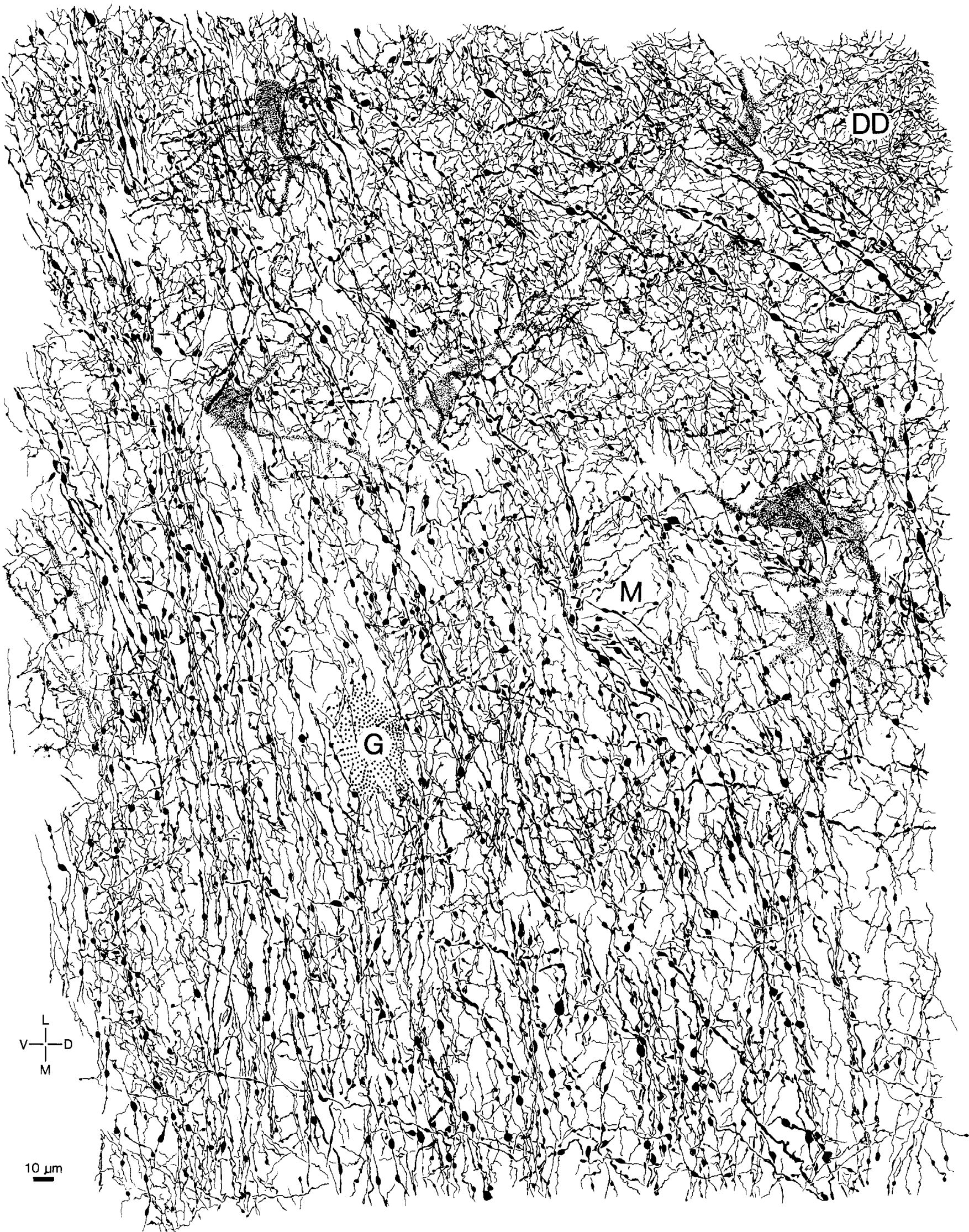

Figure 8. The texture of the neuropil at the juncture of the deep dorsal nucleus $(D D)$ and the medial division $(M)$. Every impregnated axon from a single 100- $\mu \mathrm{m}$-thick section was drawn to show the transitional zone between the fascicles of ascending brachial fibers passing mediolaterally, the smaller groups of descending fibers running orthogonal to these, and the fine, diffuse plexus of the deep dorsal nucleus (in the extreme upper right corner). Some medial division cells, including a magnocellular neuron, are also shown (fine stipple), as well as a cluster of glial cells ( $G$, coarse stipple). Semi-apochromat, $\times$ 100, N.A. 1.25. Eighteen-day-old cat, rapid Golgi method. 
(type II) may have the same targets but are much more delicate than type I axons (Fig. 4, 3). They sometimes form extensive peridendritic collaterals (Fig. 4, 3, lower right, arrow-tails).

Thick axons (type III) with limited collaterals and knobby preterminal arbors are the only ones which appear to end on (Fig. 5, 2) or near (Fig. 4, 5, upper panel) perikarya. They often emit preterminal peridendritic branches before winding along the somatic surface; some collaterals may continue toward other dendrites.

Large axons (type IV) with extensive collaterals also occur (Fig. 7A). Although not impregnated with great frequency, they are so large and extensive as to exert potentially widespread influence within the surrounding neuropil. The large central stem (about $5 \mu \mathrm{m}$ ) of each axon twists and turns like a corkscrew after entering the medial division. Progressively finer, $Y$-shaped and beaded collaterals form in the environs of the central stem. These endings occur individually or in skeins that enfold one another in labyrinthine imbrications along the distal parts of principal cell dendrites (Fig. 7A, DENDRITE).

\section{Nuclei of the brachium of the inferior colliculus}

These cell groups are embedded within the body of the inferior brachium, or beside it, as it traverses the lateral aspect of the midbrain between the inferior colliculus and the medial geniculate body. One can distinguish the interstitial nucleus of the inferior brachium and the dorsal, ventral, and medial accessory nuclei (Figs. 9 and 10). Axons ascending and descending within the inferior brachium form endings within all of these nuclei, either directly or by way of collaterals (Fig. 9, 2).

The interstitial nucleus of the inferior brachium is comprised of the neurons embedded within the brachium (Figs. 9 to 11). These cells are small- to medium-sized stellate or radiate neurons. Some resemble neurons of the adjacent midbrain tegmentum. Caudally, they become continuous with the neurons in the superficial zone of the lateral nucleus of the inferior colliculus. Rostrally, they blend in with the neuronal population in the caudal end of the medial division of the medial geniculate body. Some of the cells may even resemble certain varieties of radiate neurons in the medial division (e.g., Fig. 2, 2).Both medium-sized stellate and Golgi type II neurons also occur. The dendrites of stellate cells tend to orient either orthogonal or parallel to the brachial fibers (Fig. $11 B$ ), whereas the main axon may either ascend or descend in the brachium, sometimes forming short collaterals within the interstitial nucleus. The Golgi type II cells are quite small and have a locally arborizing axon and a lacy branching pattern of dendrites, which are not consistently oriented (Fig. 11A). In addition, there are a number of neurons with small somata less than $15 \mu \mathrm{m}$ in diameter with short, sparse dendrites, which we have not classified. Afferent axons from the lateral tegmental system form collateral endings in the interstitial nucleus en route to the dorsal nucleus (Fig. 9, 1).

The accessory nuclei of the inferior brachium. The medial accessory nucleus is located immediately medial to the main body of the brachium at a level between the caudal pole of the medial geniculate body and the rostral

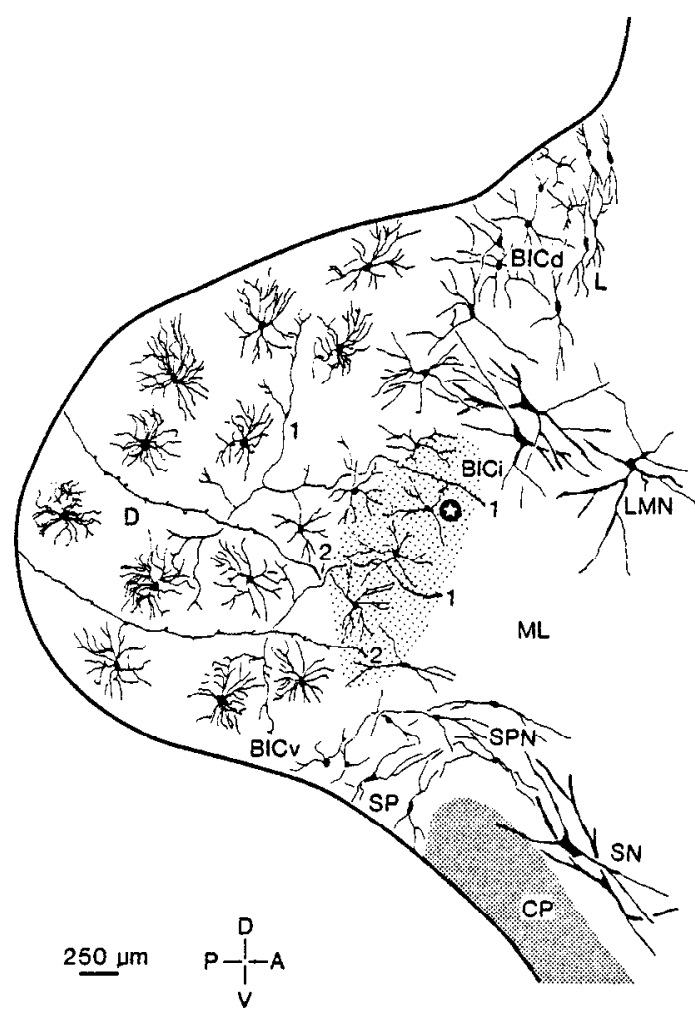

Figure 9. Principal neurons in the caudal end of the medial geniculate body. 1, Afferent axons to the dorsal nucleus $(D)$ from the lateral tegmental system with collateral twigs, one of which ends on a stellate cell (star) in the interstitial nucleus of the inferior brachium $(B I C i)$. 2, Afferent fibers with hooked appendages in the dorsal nucleus $(D)$ entering the capsule of the medial geniculate body from the brachium of the inferior colliculus. Free-hand drawing. Twenty-eight-day old cat, GolgiCox method. Redrawn from Morest (1964).

pole of the central nucleus of the inferior colliculus. Its structure has been discussed elsewhere (Morest and Oliver, 1983). The ventral accessory nucleus occupies a thin sliver of tissue in the extreme caudal tip of the medial geniculate body, where it is wedged between the caudal end of the dorsal nucleus dorsolaterally and the inferior brachium dorsomedially (Fig. 9). The neurons are small stellate cells with only a few long, radiating, sparsely branched dendrites reminiscent of those in the nearby midbrain reticular formation (Fig. 10B). The dorsal accessory nucleus nestles on the dorsal aspect of the inferior brachium, between the dorsal nucleus of the medial geniculate body and posterior nucleus limitans (Fig. 9). The principal neurons are medium-sized stellate cells, somewhat larger than those in the interstitial nucleus (Figs. 9 and $11 C$ ). There are Golgi type II cells or local circuit neurons with well developed axon collaterals, some of them with rather fantastic physiognomies (Fig. $10 C)$.

\section{Discussion}

Structure and function of the medial division of the medial geniculate body. The main finding of this study is the structural diversity of the neurons and axons in the medial division of the medial geniculate body. This contrasts with the more limited stereotypy of cells in the 


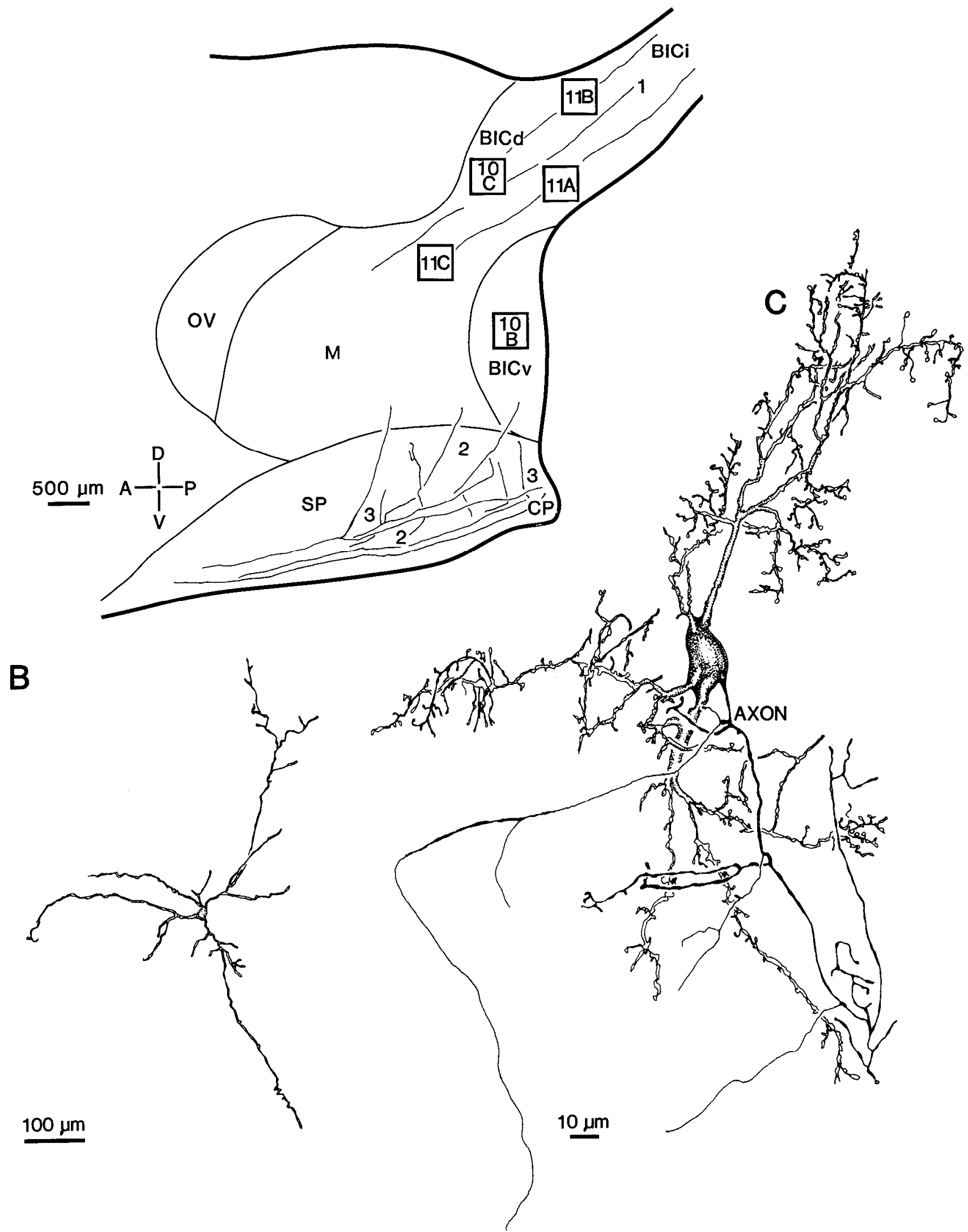

Figure 10. A, Parasagittal section through the medial geniculate body and brachium of the inferior colliculus showing the locations of drawings in Figures $10, B$ and $C$, and 11. 1, Fibers running in the inferior brachium; 2, afferent axons turning obliquely from the cerebral peduncle $(C P)$ to enter the medial geniculate body and ventral accessory nucleus of the inferior brachium $(B I C v)$ before leaving the plane of section; 3, afferent axonal collaterals forming at right angles in the region of the suprapeduncular nucleus $(S P)$ before leaving the plane of section. Free-hand drawing. Cat of unknown age, Golgi method. $B$, Stellate cell from the ventral accessory nucleus of the inferior brachium. Zeiss carbon-arc microprojector. Cat of unknown age, Golgi-Cox method. C, A small bushy neuron from the dorsal accessory nucleus of the inferior brachium. The axon forms an extensive collateral network before leaving the plane of section. Free-hand drawing. Cat of unknown age, Golgi method. 


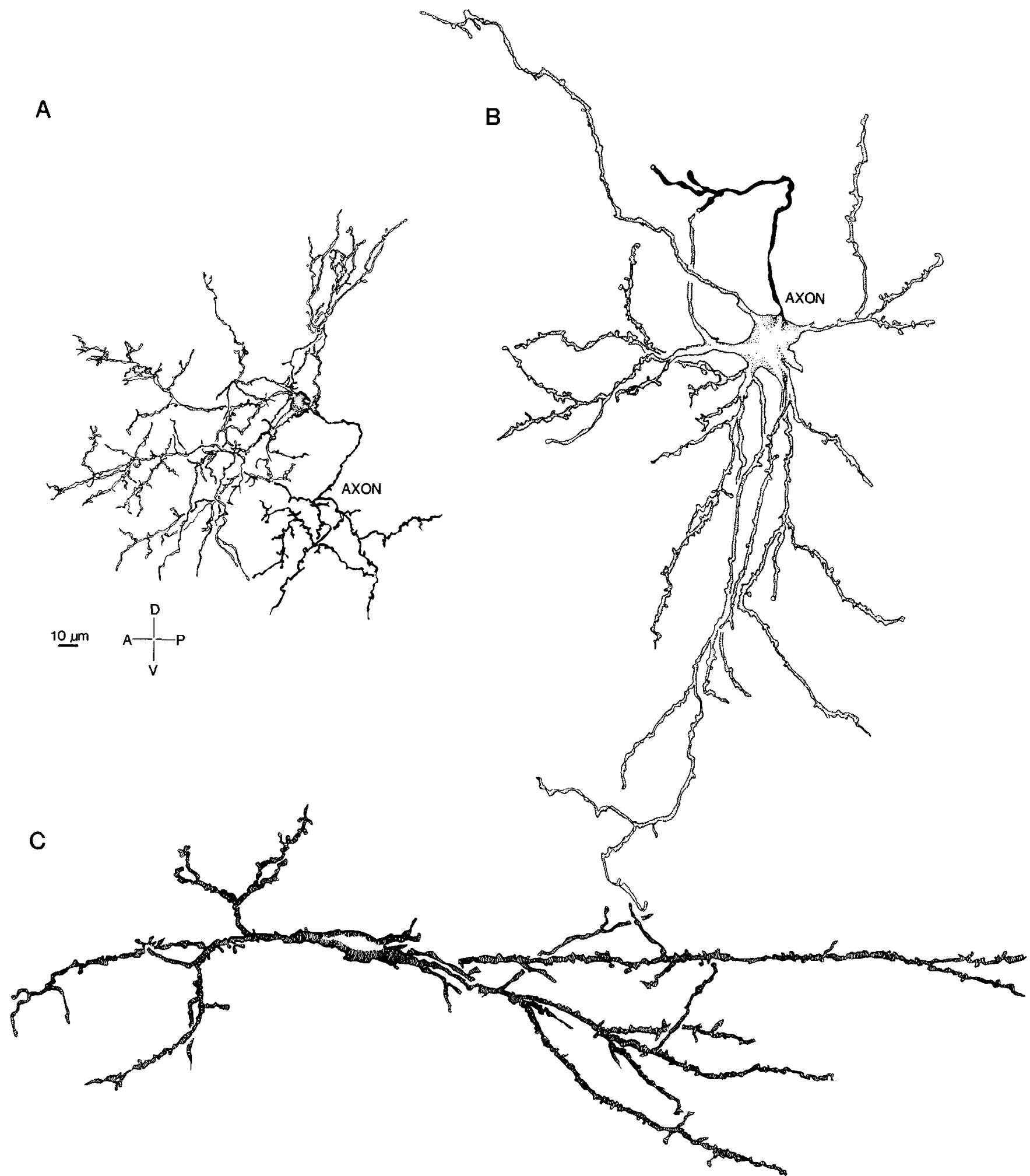

Figure 11. A, Small Golgi type II neuron from the interstitial nucleus of the inferior brachium (see Fig. 10A for location). $B$, A stellate neuron from the interstitial nucleus of the inferior brachium. The axon gives off a couple of collateral twigs before leaving the plane of section. Zeiss carbon-arc microprojector. $C$, Elongated stellate neuron from the dorsal accessory nucleus of the inferior colliculus. Zeiss carbon-arc microprojector. Cats of unknown ages, Golgi method.

ventral and the dorsal divisions. These divisions must differ fundamentally from the medial one in organization and function. Medial division cells differ in many ways from those in the other parts of the medial geniculate body. Both the ventral and dorsal divisions may be divided into discrete nuclei containing a small number of different cell types and distinct patterns of neuropil. In the medial division the different types of neurons intermingle extensively. Nevertheless, each type of neuron is surrounded by a typical pattern of neuropil, con- 
sisting of specific dendritic and axonal branching patterns. As the different types of neurons intermingle in the medial division, each one carries along its characteristic local neuropil pattern. This results in the variegated texture of the medial division neuropil, which resembles the rich-veined grain of an oak wood panel (Fig. 8). Consequently, the medial division is not readily subdivided, although regional differences appear. Caudally, there is a predominance of stellate neurons and features of the neuropil resembling the interstitial nucleus of the inferior brachium. Rostrally, bushy cells, magnocellular neurons, and other neuropil patterns prevail. The remaining cell types, including many stellate and bushy neurons, are commingled throughout the medial division.

The complexity of its neuronal architecture belies the term, "pars magnocellularis," a name used historically in reference to the largest neurons in the medial division (Rioch, 1929). This term is a misnomer, since the magnocellular neurons are only a small fraction of the population, and they are largely limited to the rostral region. On the other hand, the term, "pars principalis" (Rose and Woolsey, 1949a), does not coincide with any of the present divisions. It is wrong to divide "pars principalis" into dorsal and ventral nuclei (see Morest, 1964). The dorsal division has more types of neurons than does the ventral or medial division, but these are segregated in discrete nuclei, each having a characteristic pattern of neuronal and axonal architecture (Winer and Morest, $1978,1983 \mathrm{~b})$ as well as separate targets in the nonprimary auditory and other cortex (Winer et al., 1977; Andersen et al., 1980a). In contrast, the ventral nucleus in the ventral division contains only bushy principal neurons, which project to primary auditory cortex, and Golgi type II neurons (Morest, 1965a, 1975a; Winer et al., 1977). The tufted principal neurons are arranged in a laminar sequence, which preserves the tonotopic map represented by axons ascending from the central nucleus of the inferior colliculus (Morest, 1965a; Andersen et al., 1980b; Kudo and Niimi, 1980). In the discussion that follows, we have limited our literature references, by and large, to the cat. A discussion of the comparative anatomy can be found elsewhere (Morest, 1964; Winer, 1984; D. K. Morest and J. A. Winer, submitted for publication).

Electrophysiological studies of the medial division show that the neurons differ appreciably from those in the other divisions. Although there may be some degree of tonotopic organization of best frequency bands within the medial division, the response areas of units are reported to be broader (Aitkin, 1973) and their responses less specific (Wepsic, 1966) than those of units in the ventral (Aitkin and Webster, 1972) or dorsal (Aitkin and Prain, 1974; Birt et al., 1979; Birt and Olds, 1981) divisions. Medial division units are less likely to maintain modality specificity and are less stimulus bound; i.e., they often produce complicated and prolonged response patterns (Lippe and Weinberger, 1973a, b). It is possible that an orderly arrangement of bushy cell tufted dendrites and of axon types II to IV could provide a rough tonotopic map of frequency in the medial division, as such cells and axons are the types related to topographical maps in the main sensory nuclei. If so, the more rostral half of the medial division, where such cells are more common, might reveal a more orderly arrangement of frequencies than the caudal part, in which stellate cells predominate. On the other hand, the fibers in the caudal zone are more likely to retain their tonotopic organization (Moore and Goldberg, 1963). Medial division cells are reported to have more labile response profiles across time and to be more susceptible to classical conditioning than other medial geniculate neurons (Ryugo and Weinberger, 1978). Potentiation of responses across time has also been reported (Gerren and Weinberger, 1983). Perhaps this is related to the variety of afferent inputs to the medial division and the morphology of the ascending and descending fibers and their connections. These include ascending axons from the spinal cord (Nauta and Kuypers, 1958; Morest, 1965b; Hand and Van Winkle, 1977; Berkley, 1980), inferior colliculus (Rasmussen, 1961, 1964; Moore and Goldberg, 1963; Kudo and Niimi, 1978, 1980), nuclei of the lateral lemniscus (Kudo, 1981), vestibular system (Liedgren et al., 1976; Blum et al., 1979), and superior colliculus (Morest, 1965b; Graybiel, 1972; Graham, 1977). Descending axons from both auditory (Diamond et al., 1969) and nonauditory (Jones and Powell, 1973) cortex also occur. Thus the medial division must serve some other functions than simply auditory ones.

In view of the morphological diversity of its neurons and neuropil, as well as its pattern of connections, the medial division may not function as a unit. It seems more appropriate to consider the functional significance of the medial division in relation to that of the surrounding structures and pathways which overlap with it. The medial division is a polymodal region, in which auditory input is only one of several. Nevertheless, it is strongly associated with other auditory structures in the medial geniculate body. Thus, the medial division receives inputs of known auditory pathways from the brachium of the inferior colliculus and from the auditory cortex. Medial division neurons resemble other thalamic and medial geniculate body cells more closely than do those of the adjacent lateral mesencephalic nucleus, reticular formation, or subparafascicular or suprapeduncular nuclei (Morest, 1964). Also, the principal target of medial division axons is the auditory and periauditory cortex (Winer et al., 1977).

The medial division embodies auditory pathways which run with those of the ventral and dorsal divisions and which converge in the cortex (Knight, 1977; Reale and Imig, 1980). The somatic sensory (Scheibel et al., 1972; Donoghue et al., 1979), visual (Tusa and Palmer, 1980), and vestibular (Magnin and Kennedy, 1979) systems establish partly separate, partly overlapping channels with the auditory pathways in the mammalian thalamus (Erickson et al., 1964, 1967) and cortex (Ödqvist et al., 1975). The primary auditory pathway is represented by the sharply tuned units of the ventral nucleus of the medial geniculate body (Aitkin and Webster, 1972), which receive input mainly from the central nucleus of the inferior colliculus and project to primary auditory cortex so as to preserve the tonotopic organization with high fidelity (Woolsey, 1961, 1964; Winer et al., 1977; Andersen et al., 1980a, b; Imig and Reale, 1980). The dorsal division receives major, if not dominant, 
auditory input from the lateral tegmental system (Morest, 1965b) and inferior colliculus (Morest, 1965b; Kudo and Niimi, 1978, 1980) and projects to all areas of nonprimary auditory cortex. This suggests that it contributes to a parallel, nonprimary auditory pathway. It may be that individual nuclei of the dorsal division form a number of subsidiary parallel projections. A similar concept may hold for the organization of the ascending pathways to the "core" and "belt" areas of the sensory neocortex (Diamond and Chow, 1962) or lemniscal line and lemniscal adjunct pathways (Graybiel, 1972). In the medial division an even greater number of parallel pathways could be found, including those arising from nonauditory modalities. The degree to which such parallel pathways could be preserved in the cerebral cortex remains to be determined. The cortical projections of the medial division include all auditory cortical areas as well as periauditory cortex (Winer et al., 1977; Spreafico et al., 1981). There is evidence that some parallel pathways can be preserved in the cerebral cortex. Thus the cortical projection from the medial division terminates diffusely in layers I and VI, whereas the other auditory pathways end primarily in layers III and IV (Sousa-Pinto, 1973; Niimi and Naito, 1974). On the other hand, there is ample opportunity for convergence between the various pathways in the medial division and its cortical projection sites. There is electrophysiological evidence for multimodal activation of cells in the medial division (Poggio and Mountcastle, 1960; Wepsic, 1966; Raffaele et al., 1969; Curry, 1972). It remains to relate such electrophysiological findings to specific morphological types of neurons.

The laminar terminations of thalamocortical afferents from the medial division to layers I and VI parallel the projections of the opossum central intralaminar nucleus, which is considered part of the unspecific system receiving input from several modalities, whereas the ventrobasal nuclei project to layer IV (Killackey and Ebner, 1972). Lesions of the tree shrew pulvinar nucleus produce degeneration chiefly in layers IV and III (Harting et al., 1973). In the primate the pulvinar nucleus projects densely to layer IV, less strongly to deep layer III, and sparsely to layers I and VI (Glendenning et al., 1975). Primate lateral geniculate axons terminate in layer IV and, to a lesser degree, in parts of layer III (Glendenning et al., 1976; Fitzpatrick et al., 1983). These observations suggest that the cortical projections of the main sensory nuclei center on layer IV of their respective areas, whereas those of the associated nuclei favor layers I and VI in their respective areas. No doubt further correlations will be made to distinguish the laminar projection patterns of the specific cell types.

Opportunities for interaction between the pathways of the medial, dorsal, and ventral divisions in the thalamus are limited. Certain neurons in the medial division do project to the dorsal (Morest, 1965b, Text-Fig. 2, e) or ventral (Morest, 1975a, Fig. 3, c) divisions. Also, local circuit interneurons have been described throughout the medial geniculate body (Morest, 1971, 1975a, c; Majorossy and Kiss, 1976a, b; Winer and Morest, 1978, 1983a, b; D. K. Morest and J. A. Winer, submitted for publication). However, there does not appear to be an extensive system of interneurons interconnecting divisions and subdivisions in the medial geniculate body. There is no evidence for connections between the dorsal and ventral divisions. Thus, the projections of the ventral, dorsal, and medial divisions maintain a largely parallel organization. However, at the level of the cerebral cortex opportunities for both parallel and overlapping interactions arise, and each subdivision of auditory cortex is allied with the others. Moreover, the medial division provides common input to all areas of auditory cortex.

The neuronal morphology of the medial division does not seem to have features that are uniquely auditory, as, for example, in the case of the end bulbs of Held and the octopus cells in the cochlear nucleus (Morest, 1975b). The local circuit cells and the bushy neurons are structurally analogous to specific cell types in the main sensory nuclei of the thalamus; i.e., the ventral nucleus of the medial geniculate body, the dorsal nucleus of the lateral geniculate body, and the ventroposterior nuclei of the ventrobasal complex. As a matter of fact, structurally analogous neurons occur throughout the associated nuclei of the dorsal division-lateral posterior-pulvinar complex. These neurons are usually associated with synaptic nests and sequential synaptic organization involving Golgi type II cells and dendritic junctions (LeVay, 1971; Morest, 1971; Ralston, 1971). In other words, these neuronal types are common elements of thalamic nuclei, except for the intralaminar group. As such, they may embody principles common to thalamic function. This has led us to point out certain patterns of organization in the posterior thalamus which may provide a basis for correlating its structural architecture with its connections and functional attributes.

Historical note on the organization of the thalamus. It will not escape the reader's notice that the concepts of the dorsal thalamus discussed here represent a departure from the classical schemes. Nevertheless, the present scheme is only one effort in a long history of attempts to classify the thalamic nuclei. Although it would not be appropriate to review this history in detail here, we should point out that our concept of thalamic organization is based on a definition of cell types and represents an extension of the previous ones, which were based on cytoarchitectonics and connections.

The early classical views were dominated by the cytoarchitectonics based on Nissl's stain and led to the concept of the thalamus as a mosaic of discrete, individually delineated cell groups. Sometimes these cytoarchitectonic parcellations strained credulity by the sheer number of subdivisions proposed in a purely descriptive way without much idea of their functional significance, but time has proved their validity in many cases (e.g., Rose, 1935). On the other hand, this approach went in parallel with contemporary studies of cortical cytoarchitectonicists and of physiologists and neurologists interested in cortical localization of function. These studies led to the concept of the sensory and association areas, the latter receiving their input from cortical association fibers rather than from the thalamus. However, as connectional studies progressed, it became clear that almost all cortical areas receive thalamic input. Moreover, Rose and Woolsey (1943) concluded that "all dorsal thalamic 
nuclei are telencephalic dependencies; most of them ... cortical." Thus it became possible to distinguish two classes of thalamic nuclei, those which projected to the main sensory cortex and those projecting to so-called association cortex. In these and in subsequent years a number of dichotomies were distinguished in the thalamic nuclei on the basis of new information about their connections, including specific and nonspecific, or diffuse, depending on the distribution of the thalamocortical projections (e.g., Morison and Dempsey, 1942), extrinsic and intrinsic, depending on the presence or absence of ascending afferents (e.g., Rose and Woolsey, 1949b), and, in recent years, lemniscal and extralemniscal or lemniscal line and lemniscal adjunct, depending on their relations to the main sensory pathways (e.g., Herrick and Bishop, 1958; Nauta and Kuypers, 1958; Morest, 1965b; Graybiel, 1972), and the related phylogenetic concept of core and belt (e.g., Diamond and Chow, 1962; Casseday et al., 1976).

The present scheme is consistent with those of recent years, in that a dichotomy is recognized between the main sensory and the associated thalamic nuclei, similar to that of core and belt or lemniscal line and lemniscal adjunct. However, the present dichotomy is based primarily on fundamental differences in the synaptic organization of different types of neurons and patterns of neuropil, morphologically defined. It is interesting that some of the first attempts to study thalamic organization were based on morphological definitions of cell types with the Golgi methods. Thus, Marchi (cited by Kölliker, 1896, p. 519) and Kölliker (1896) described Buschzellen and Sternzellen in the thalamus, which would correspond to our bushy and stellate types. Unlike the preceding schemes, the present one takes into account another order of organization superimposed on the mosaic of thalamic cell groups. Thus, the concept of aligned and unaligned cell groups within the associated nuclei needs to be considered in correlating the architectonics and connections of the thalamus to the cellular basis for information processing in sensory systems.

Present view of thalamic organization. In making our correlations, we rely on a great deal of data on the structure, connections, and electrophysiology of the medial geniculate body and the neighboring thalamic nuclei. Much of this data has been referenced in the preceding portion of this paper and in a number of companion studies (Morest, 1964, 1965a, b, 1971, 1975a, b; Winer and Morest, 1983a, b; Winer, 1984; D. K. Morest and J. A. Winer, submitted for publication). Consequently, in the following we have excluded all but a few literature references, so as to concentrate on the conceptual exposition.

The neurons of the medial and dorsal divisions of the medial geniculate body, together with those of the lateral posterior and pulvinar regions, comprise a complex of nuclei associated with the main sensory groups of the thalamus (Kreindler et al., 1968). These associated sensory nuclei contain predominantly stellate neurons with the radiate pattern of dendritic branching along with a smaller population of bushy neurons. Analogous types of stellate neurons characterize each of the associated sensory nuclei. Hence the medial and dorsal divisions of the medial geniculate body represent portions of a morphological field extending from the pulvinar through the lateral posterior-suprageniculate complex to the caudal pole of the medial geniculate body. In other words, the dorsal nucleus of the medial geniculate body and the pulvinar are part and parcel of the same nuclear complex. The characteristic cell types of the associated sensory complex are distinct from those of the intralaminar group and the main sensory nuclei. The intralaminar group includes the nucleus limitans and its posterior extension in the medial geniculate body; they typically contain principal neurons with few, poorly branched, long radiating dendrites. Entirely different kinds of neurons characterize the main sensory nuclei, where each nucleus contains analogous types of bushy principal neurons having typical, tufted or disc-shaped dendrites associated with small Golgi type II cells. In these nuclei laminar arrangements of bushy principal neurons can be correlated with well developed topographical organizations. Bushy neurons also occur in the associated sensory nuclei, but these cells are not disc shaped, and the tufted form of their dendritic branching is less fully expressedeven somewhat intermediate to the radiate and tufted patterns.

The aligned cell groups are portions of the associated nuclei more closely linked to one or another of the main sensory pathways (Fig. 12). In the auditory pathways a portion of the medial division and of the suprageniculate and dorsal nuclei is closely associated with the ventral nucleus of the medial geniculate body. In the somatic sensory pathways, portions of the medial division and the suprageniculate nucleus are allied with the ventrobasal nuclei. In the visual pathway the perigeniculate and pulvinar-lateral posterior-suprageniculate nuclei are aligned with the dorsal nucleus of the lateral geniculate body. A part of each of these aligned groups overlaps within the associated sensory complex (Fig. 12). This region of overlap is known to contain neurons with polysensory representations. These neurons constitute the unaligned cell groups. The unaligned cell groups receive convergent projections ascending from one or more of the auditory, visual, somatic sensory, vestibular, and reticular system pathways. Presumably, these unaligned cell groups provide diverging projections to widespread targets in the cerebral cortex. By comparison, the aligned cell groups may receive more restricted inputs, associated with the main sensory pathways, but they participate in more or less divergent projections to the cortex. In contrast, the main sensory nuclei maintain relatively restricted connections with the main sensory pathways and primary cortical areas. In the present study we have been unable to assign the aligned and unaligned groups to separate subdivisions of the associated sensory complex. The representation of the aligned and unaligned cell groups in Figure 12 is intended as only an approximation and is not the result of systematic mapping, either anatomical or electrophysiological. The "core" and "belt" concept of Diamond and Chow (1962) has no doubt stimulated many of the detailed functional mapping studies of the cortex. Likewise, the present scheme should provide a propaedeutic for more detailed maps in future studies of the thalamus. However, such maps 




should include correlations of unit response patterns with specific types of neurons.

The locations within the associated sensory nuclei of unit recordings from electrophysiological studies have not been reported with much precision. Nevertheless, the available observations show that auditory inputs are more dominant in the caudal and lateral regions of the medial and dorsal divisions of the medial geniculate body, adjacent to the ventral nucleus; that somatic sensory inputs tend to collect rostrally and medially in the medial and dorsal divisions, adjacent to the ventrobasal complex; and that visual inputs prevail dorsally and laterally in the suprageniculate-lateral posterior-pulvinar complex, adjacent to the lateral geniculate body. Accordingly, the aligned cell groups should be prevalent in those regions (Fig. 12, numbered loci). The distribution of the unaligned cell groups is less certain. Presumably, they would extend through the central portions of the associated sensory complex, where the available electrophysiological and neuroanatomical literature suggests that 
many polysensory neurons are located (Fig. 12, circled loci). However, the distribution of such cells has not been mapped systematically, and it may well include more peripheral portions of the associated sensory complex. Thus the area indicating the unaligned cell groups in Figure 12 is not meant to imply the existence of an architectural boundary but, rather, to suggest a tendency in the distribution of the unaligned cell groups, which, no doubt, overlap with the aligned cell groups. Although it may be possible to define further subdivisions, in our view it is likely that these cell groups correspond to different cell types, which may or may not overlap in their distribution.

The types of neurons common to the main sensory nuclei consist of the bushy thalamocortical neurons and small Golgi type II cells which form a characteristic synaptic configuration of sequentially arranged axodendritic and dendrodendritic synapses involving the sensory afferent axons and the dendrites and axons of Golgi type II neurons (Morest, 1975a, b, c). The physiological implications of such a structural plan for the medial geniculate body have been discussed elsewhere (Morest, 1975a). The synaptic arrangement of tufted dendrites can provide a high degree of specificity, synaptic security, and tonotopic organization in the main ascending afferent auditory pathway in the ventral nucleus, while local circuits could introduce a limited signal transformation (Morest, 1965b, 1971, 1975a, b). We would expect analogous considerations to apply to the homologous neurons of the ventrobasal complex (McAllister and Wells, 1981) and lateral geniculate body (Guillery, 1966). This is not to imply that each of the main sensory nuclei consists only of bushy principal cells or that stellate neurons are never unimodal. For example, both bushy and stellate neurons exist in the small-cell layers of the lateral geniculate body. Although both types of cells may receive purely visual inputs, there is some evidence that they differ in their physiological properties and cortical connections (e.g., Leventhal, 1979; Friedlander et al., 1981). On the other hand, the large intralaminar stellate neurons spanning different layers in the lateral geniculate body may receive more heterogeneous input than do the bushy cells, which are confined to individual laminae.

An analogous bushy pattern of synaptic organization has been observed in the dorsal nucleus of the medial geniculate body (J. A. Winer and D. K. Morest, unpublished observations) and elsewhere in the associated sensory nuclei (e.g., Majorossy et al., 1965; Hajdu et al., 1974 , in the pulvinar). Although this pattern may not be so well developed as in the main sensory nuclei, we think that it may be represented by the bushy neurons and small Golgi type II cells, which, accordingly, do not appear to be as prominent in the associated cell groups. Insofar as these cell groups exhibit any physiological properties comparable to those of the main sensory nuclei, e.g., certain sharply tuned units (Calford and Webster, 1981), we would tend to attribute them to the bushy neurons. In any case, the structural organization of the associated nuclei, as evinced by the dorsal nucleus of the medial geniculate body, must be significantly modified by the presence of the stellate neurons and different varieties of axons and inputs, compared to the main sensory nucleus. We suggest that stellate cells and their inputs provide a basis for the more diversified and labile physiological properties of auditory units observed in the dorsal division of the medial geniculate body (see Winer and Morest, 1983a; D. K. Morest and J. A. Winer, submitted for publication). This is likely to be so, because we have observed that the degree of divergence and overlap of the ascending afferents is greater for stellate than for bushy cells.

In the medial division of the medial geniculate body the cell types are more heterogeneous, but the dendritic branching patterns are not nearly so well developed. Nevertheless, weakly tufted and irregularly radiate neurons in the caudal and lateral regions could provide for acoustic response patterns similar to those of the aligned cell groups of the dorsal division. Similar kinds of neurons may be aligned with the somatic sensory pathways in the medial division, especially the magnocellular neurons in the rostral region, and in the suprageniculatelateral posterior complex. Physiological activity here is dominated by somatic sensory input but often lacks the high degree of specificity and sharp tuning characteristic of many neurons in the ventrobasal complex. An analogous situation could prevail in the pulvinar-lateral posterior complex, where many, predominantly visual units lack the synaptic security of neurons, such as the X cells, recorded in the dorsal nucleus of the lateral geniculate body.

The unaligned cell groups throughout the medial division and in the associated sensory complex would correspond to those neurons with polysensory inputs, with a low degree of synaptic security and readily modifiable response patterns (as, for example, by behavioral conditioning). We have very few clues as to the identity of the types of neurons involved. By comparison to the aligned cell groups and main sensory nuclei, one might expect the stellate neurons or the elongate cells to provide appropriate targets for the requisite degree of afferent convergence. Such neurons could project to widespread regions in the cerebral cortex, either by way of axon collaterals or, as seems more likely, by differential projections from individual neurons or groups.

The physiological properties of the unaligned cell groups no doubt reflect their differing connections. Unit electrophysiological response patterns would exhibit loss of modality specificity, large, often bilateral receptive fields, long latencies, increased variability of responsiveness, and loss of topographical organization. This contrasts with the main sensory nuclei, whereas the aligned cell groups in the associated sensory complex would tend to be intermediate or mixed in their electrophysiological properties.

The associated sensory nuclei also probably differ in their embryology. For example, neurons of the medial division appear to form earlier than those of the ventral nucleus in the mouse (Angevine, 1970), but not in the rat (Altman and Bayer, 1979). There is evidence that the principal neurons in the dorsal division differentiate later than those of the ventral nucleus (Morest, 1969; D. K. Morest, unpublished observations), and the thalamocortical projections from the ventral nucleus may appear sooner than those from the rest of the medial geniculate 
body. In comparative anatomical studies the homologous cell types and nuclear groups can be identified in the main sensory and associated nuclei, where they exhibit analogous morphological features and connections (e.g., Le Gros Clark, 1932, 1933; Morest, 1965c; Oliver and Hall, 1978a, b; Winer and Morest, 1979; Oliver, 1982; D. K. Morest and J. A. Winer, submitted for publication). This raises the possibility that the associated sensory nuclei have a phylogenetic history different from that of the main sensory groups in the evolution of thalamic organization.

\section{References}

Aitkin, L. M. (1973) Medial geniculate body of the cat: Responses to tonal stimuli of neurons in the medial division. J. Neurophysiol. 36: 275-283.

Aitkin, L. M., and S. M. Prain (1974) Medial geniculate body: Unit responses in the awake cat. J. Neurophysiol. 37: 512521.

Aitkin, L. M., and W. R. Webster (1972) Medial geniculate body of the cat: Organization and response to tonal stimuli in the ventral division. J. Neurophysiol. 35: 365-380.

Altman, J., and S. A. Bayer (1979) Development of the diencephalon of the rat. V. Thymidine-radiographic observations on internuclear and intranuclear gradients in the thalamus. J. Comp. Neurol. 188: 473-500.

Andersen, R. A., P. L. Knight, and M. M. Merzenich (1980a) The thalamocortical and corticothalamic connections of AI, AII, and the anterior auditory field (AAF) in the cat: Evidence for two largely segregated systems of connections. J. Comp. Neurol. 194: 663-701.

Andersen, R. A., G. L. Roth, L. M. Aitkin, and M. M. Merzenich (1980b) The efferent projections of the central nucleus and pericentral nucleus of the inferior colliculus of the cat. J. Comp. Neurol. 194: 649-662.

Angevine, J. B. (1970) Time of neuron origin in the diencephalon of the mouse. An autoradiographic study. J. Comp. Neurol. 139: 129-188.

Berkley, K. J. (1980) Spatial relationships between the terminations of somatic sensory and motor pathways in the rostral brainstem of cats and monkeys. I. Ascending somatic sensory inputs to lateral diencephalon. J. Comp. Neurol. 193: 283317.

Birt, D., and M. Olds (1981) Associative response changes in lateral midbrain tegmentum and medial geniculate during differential appetitive conditioning. J. Neurophysiol. 46: 1039-1055.

Birt, D., R. Nienhuis, and M. Olds (1979) Separation of associative from non-associative short latency changes in medial geniculate and inferior colliculus during differential conditioning. Brain Res. 167: 129-138.

Blum, P. S., L. D. Abraham, and S. Gilman (1979) Vestibular, auditory, and somatic sensory input to the posterior thalamus of the cat. Exp. Brain Res. 34: 1-9.

Calford, M. B., and W. R. Webster (1981) Auditory representation within principal division of cat medial geniculate body: An electrophysiological study. J. Neurophysiol. 45: 10131028.

Casseday, J. H., I. T. Diamond, and J. K. Harting (1976) Auditory pathways to the cortex in Tupaia glis. J. Comp. Neurol. 166: 303-340.

Curry, M. J. (1972) The exteroreceptive properties of neurones in the somatic part of the posterior group. Brain Res. 44: $463-481$.

Diamond, I. T., and K. L. Chow (1962) Biological psychology. In Psychology: A Study of a Science. Vol. 4: Study II, S. Koch, cd., pp. 158 241, McGraw-Hill Book Co., New York.

Diamond, I. T., E. G. Jones, and T. P. S. Powell (1969) The projection of the auditory cortex upon the diencephalon and brain stem in the cat. Brain Res. 15: 305-340.

Donoghue, J. P., K. L. Kerman, and F. F. Ebner (1979) Evidence for two organizational plans within the somatic sensory-motor cortex of the rat. J. Comp. Neurol. 183: 647-664.

Erickson, R. P., J. A. Jane, R. E. Waite, and I. T. Diamond (1964) Single neuron investigation of sensory thalamus of the opossum. J. Neurophysiol. 27: 1026-1047.

Erickson, R. P., W. C. Hall, J. A. Jane, and I. T. Diamond (1967) Organization of posterior dorsal thalamus of the hedgehog. J. Comp. Neurol. 131: 103-130.

Erulkar, S. D. (1975) Physiological studies of the inferior colliculus and medial geniculate complex. In Handbook of Sensory Physiology. Vol. 5, Pt. 2: Auditory System. Physiology (CNS), Behavioral Studies, Psychoacoustics, W. D. Neff and W. D. Keidel, eds., pp. 145-198, Springer-Verlag, Berlin.

Fitzpatrick, D., K. Itoh, and I. T. Diamond (1983) The laminar organization of the lateral geniculate body and the striate cortex in the squirrel monkey (Saimiri sciureus). J. Neurosci. 3: $673-702$.

Friedlander, M. J., C. -S. Lin, L. R. Stanford, and S. M. Sherman (1981) Morphology of functionally identified neurons in lateral geniculate nucleus of the cat. J. Neurophysiol. 46: $80-129$.

Gerren, R. A., and N. M. Weinberger (1983) Long term potentiation in the magnocellular medial geniculate nucleus of the anesthetized cal. Brain Res. 265: 138-142.

Glendenning, K. K., J. A. Hall, I. T. Diamond, and W. C. Hall (1975) The pulvinar nucleus of Galago senegalensis. J. Comp. Neurol. 161: 419-458.

Glendenning, K. K., E. A. Kofron, and I. T. Diamond (1976) Laminar organization of projections of the lateral geniculate nucleus to the striate cortex in Galago. Brain Res. 105: 538546.

Graham, J. (1977) An autoradiographic study of the efferent connections of the superior colliculus in the cat. J. Comp. Neurol. 173: 629-654.

Graybiel, A. M. (1972) Some fiber pathways related to the posterior thalamic region in the cat. Brain Behav. Evol. 6 : 363-393.

Guillery, R. W. (1966) A study of Golgi preparations from the dorsal lateral geniculate nucleus of the adult cat. J. Comp. Neurol. 128: 21-50.

Hajdu, F., G. Somogyi, and T. Tömböl (1974) Neuronal and synaptic arrangement in the lateral posterior-pulvinar complex of the thalamus in the cat. Brain Res. 73: 89-104.

Hand, P. J., and T. Van Winkle (1977) The efferent connections of the feline nucleus cuneatus. J. Comp. Neurol. 171: 83-110.

Harting, J. K., I. T. Diamond, and W. C. Hall (1973) Anterograde degeneration study of the cortical projections of the lateral geniculate and pulvinar nuclei in the tree shrew (Tupaia glis). J. Comp. Neurol. 150: 393-440.

Herrick, C. J., and G. H. Bishop (1958) A comparative survey of the spinal lemniscus systems. In Reticular Formation of the Brain, H. H. Jasper, L. D. Proctor, R. S. Knighton, W. C. Noshay, and R. T. Costello, eds., pp. 353-360, Little, Brown and Co., Boston.

Imig, T. J., and R. A. Reale (1980) Patterns of cortico-cortical connections related to tonotopic maps in cat auditory cortex. J. Comp. Neurol. 192: 293-332.

Jones, E. G., and T. P. S. Powell (1973) Anatomical organization of the somatosensory cortex. In Handbook of Sensory Physiology. Vol. 2: Somatosensory System, A. Iggo, ed., pp. 573-620, Springer-Verlag, Berlin.

Killackey, H. P., and F. F. Ebner (1972) Two different types of 
thalamocortical projections to a single cortical area in mammals. Brain Behav. Evol. 6: 141-169.

Knight, P. L. (1977) Representation of the cochlea within the anterior auditory field (AAF) of the cat. Brain Res. 130: 447467.

Kölliker, A. (1896) Handbuch der Gewebelehre des Menschen, 6. Aufl., Bd. 2, Engelmann, Leipzig.

Kreindler, A., E. Crighel, and C. Marinchescu (1968) Integrative activity of the thalamic pulvinar lateralis complex and interrelations with the neocortex. Exp. Neurol. 22: 423-435.

Kudo, M. (1981) Projections of the nuclei of the lateral lemniscus in the cat: An autoradiographic study. Brain Res. 221: 57-69.

Kudo, M., and K. Niimi (1978) Ascending projections of the inferior colliculus onto the medial geniculate body of the cat studied by anterograde and retrograde tracing techniques. Brain Res. 155: 113-117.

Kudo, M., and K. Niimi (1980) Ascending projections of the inferior colliculus in the cat: An autoradiographic study. J. Comp. Neurol. 191: 545-556.

Le Gros Clark, W. E. (1932) The structure and connections of the thalamus. Brain 55: 406-470.

Le Gros Clark, W. E. (1933) The medial geniculate body and the nuclei isthmi. J. Anat. (Lond.) 67: 536548.

LeVay, S. (1971) On the neurons and synapses of the lateral geniculate nucleus of the monkey and the effects of eye enucleation. Z. Zellforsch. 113: 396-419.

Leventhal, A. G. (1979) Evidence that different classes of relay cells of the cat's lateral geniculate nucleus terminate in different layers of the striate cortex. Exp. Brain Res. 37: 349372.

Liedgren, S. R. C., K. Kristensson, B. Larsby, and L. M. Ödqvist (1976) Projections of thalamic neurons to cat primary vestibular cortical fields studied by means of retrograde axonal transport of horseradish peroxidase. Exp. Brain Res. 24: 237243.

Lippe, W. R., and N. M. Weinberger (1973a) The distribution of click evoked activity within the medial geniculate body of the anesthetized cat. Exp. Neurol. 39: 507-523.

Lippe, W. R., and N. M. Weinberger (1973b) The distribution of sensory evoked activity within the medial geniculate body of the anesthetized cat. Exp. Neurol. 40: 431-444.

Magnin, M., and H. Kennedy (1979) Anatomical evidence of a third ascending vestibular pathway involving the ventral lateral geniculate nucleus and the intralaminar nuclei of the cat. Brain Res. 171: 523-529.

Majorossy, K., and A. Kiss (1976a) Synaptic patterns of neuron arrangement and of synaptic articulation in the medial geniculate body. Exp. Brain Res. 26: 1-17.

Majorossy, K., and A. Kiss (1976b) Types of interneurons and their participation in the neuronal network of the medial geniculate body. Exp. Brain Res. 26: 19-37.

Majorossy, K., M. Rethélyi, and J. Szentágothai (1965) The large glomerular synapse of the pulvinar. J. Hirnforsch. 7: 415-432.

McAllister, J. P., and J. Wells (1981) The structural organization of the ventral posterolateral nucleus in the rat. J. Comp. Neurol. 197: 271-301.

Moore, R. Y., and J. M. Goldberg (1963) Ascending projections of the inferior colliculus in the cat. J. Comp. Neurol. 121: $109-136$.

Morest, D. K. (1964) The neuronal architecture of the medial geniculate body of the cat. J. Anat. (Lond.) 98: 611-630.

Morest, D. K. (1965a) The laminar structure of the medial geniculate body of the cat. J. Anat. (Lond.) 99: 143-160.

Morest, D. K. (1965b) The lateral tegmental system of the midbrain and the medial geniculate body: Study with Golgi and Nauta methods in cat. J. Anat. (Lond.) 99: 611-634.
Morest, D. K. (1965c) Identification of homologous neurons in the posterolateral thalamus of the cat and Virginia opossum. Anat. Rec. 151: 390-391.

Morest, D. K. (1969) The growth of dendrites in the mammalian brain. Z. Anat. Entwicklungsgesch. 128: 290-317.

Morest, D. K. (1971) Dendrodendritic synapses of cells that have axons: The fine structure of the Golgi type II cell in the medial geniculate body of the cat. Z. Anat. Entwicklungsgesch. 133: 216-246.

Morest, D. K. (1975a) Synaptic relationships of Golgi type II cells in the medial geniculate body of the cat. J. Comp. Neurol. 162: 157-194.

Morest, D. K. (1975b) Structural organization of the auditory pathways. In The Nervous Syslem. Vol. 3: Human Communication and Its Disorders, D. B. Tower, ed., pp. 19-29, Raven Press, New York.

Morest, D. K. (1975c) Local circuit neurons in the medial geniculate body of the cat. Neurosci. Res. Program Bull. 13: 367-377.

Morest, D. K. (1981) The Golgi methods. In Techniques in Neuroanatomical Research, C. Heym and W. G. Forssmann, eds., pp. 124-137, Springer-Verlag, Heidelberg.

Morest, D. K., and R. R. Morest (1966) Perfusion-fixation of the brain with chrome-osmium solutions for the rapid Golgi method. Am. J. Anat. 118: 811-832.

Morest, D. K., and D. L. Oliver (1983) The neuronal architecture of the inferior colliculus of the cat-Defining the functional morphology of the auditory midbrain. J. Comp. Neurol., in press.

Morison, R. S., and E. W. Dempsey (1942) A study of the thalamo-cortical relations. Am. J. Physiol. 135: 281-292.

Nauta, W. J. H., and H. G. J. M. Kuypers (1958) Some ascending pathways of the brain stem reticular formation. In Reticular Formation of the Brain, H. H. Jasper, L. D. Proctor, R. S. Knighton, W. C. Noshay, and R. T. Costello, eds., pp. 3-30, Little, Brown and Co., Boston.

Niimi, K., and F. Naito (1974) Cortical projections of the medial geniculate body in the cat. Exp. Brain Res. 19: 326-342.

Ödqvist, L. M., S. R. C. Liedgren, B. Larsby, and L. Jerlvall (1975) Vestibular and somatosensory inflow to the vestibular projection area in the post cruciate dimple region of the cat cerebral cortex. Exp. Brain Res. 22: 185-196.

Oliver, D. L. (1982) A Golgi study of the medial geniculate body in the tree shrew (Tupaia glis). .J. Comp. Neurol. 209: 1-16.

Oliver, D. L., and W. C. Hall (1978a) The medial geniculate body of the tree shrew, Tupaia glis. I. Cytoarchitecture and midbrain connections. J. Comp. Neurol. 182: 423-458.

Oliver, D. L., and W. C. Hall (1978b) The medial geniculate body of the tree shrew, Tupaia glis. II. Connections with the neocortex. J. Comp. Neurol. 182: 459-494.

Poggio, G. F., and V. B. Mountcastle (1960) A study of the funclional contribution of the lemniscal and spinothalamic systems to somatic sensibility. Central nervous mechanisms in pain. Bull. Johns Hopkins Hosp. 106: 266-316.

Raffaele, R., F. Santangelo, S. Sapienza, and A. Urbano (1969) Analisi elettrofisiologica della afferenze somatiche alla porzione magnocellulare del corpo geniculato mediale nel gatto. Boll. Soc. Ital. Biol. Sper. 45: 1456-1458.

Ralston, H. J., III (1971) Evidence for presynaptic dendrites and a proposal for their mechanism of action. Nature (Lond.) 230: 585-587.

Ramon-Moliner, E. (1962) An attempt at classifying nerve cells on the basis of their dendritic patterns. J. Comp. Neurol. 119: 211-227.

Ramón y Cajal, S. (1911) Histologie du Système Nerveux de l'Homme et des Vertébrés, Vol. II, L. Azoulay, transl., Instituto Ramón y Cajal, Madrid (1972 reprint).

Rasmussen, G. L. (1961) Distribution of fibers originating from 
the inferior colliculus. Anat. Rec. 139: 266.

Rasmussen, G. L. (1964) Anatomic relationships of the ascending and descending auditory systems. In Neurological Aspects of Auditory and Vestibular Disorders, W. S. Fields and B. R. Alford, eds., pp. 5-19, Charles C Thomas, Springfield, IL.

Reale, R. A., and T. J. Imig (1980) Tonotopic organization in auditory cortex of the cat. J. Comp. Neurol. 192: 265-292.

Rioch, D. McK. (1929) Studies on the diencephalon of carnivora. Part I. The nuclear configuration of the thalamus, epithalamus, and hypothalamus of the dog and cat. J. Comp. Neurol. 49: 1-119.

Rose, J. E., and C. N. Woolsey (1943) A study of thalamocortical relations in the rabbit. Bull. Johns Hopkins Hosp. 73: 65-128.

Rose, J. E., and C. N. Woolsey (1949a) The relations of thalamic connections, cellular structure, and evokable electrical activity in the auditory region of the cat. J. Comp. Neurol. 91: 441-466.

Rose, J. E., and C. N. Woolsey (1949b) Organization of the mammalian thalamus and its relationships to the cerebral cortex. Electroencephalogr. Clin. Neurophysiol. 1: 391-404.

Rose, M. (1935) Das Zwischenhirn des Kaninchens. Mem. Acad. Sci. Cracovie, B-Sci. Nat. 8: 53-108.

Ryugo, D. K., and N. M. Weinberger (1978) Differential plasticity of morphologically distinct neuron populations in the medial geniculate body of the cat during classical conditioning. Behav. Biol. 22: 275-301.

Scheibel, M. E., A. B. Scheibel, and T. H. Davies (1972) Some substrates for centrifugal control over thalamic cell ensembles. In Corticothalamic Projections and Sensorimotor Activities, T. L. Frigyesi, E. Rinvik, and M. D. Yahr, eds., pp. 131156, Raven Press, New York.

Sousa-Pinto, A. (1973) Cortical projections of the medial geniculate body of the cat. Adv. Anat. Embryol. Cell Biol. 48: $1-42$.

Spreafico, R., N. L. Hayes, and A. Rustioni (1981) Thalamic projections to the primary and secondary somatosensory cortices in cat: Single and double retrograde studies. J. Comp. Neurol. 203: 67-90.
Tusa, R. J., and L. A. Palmer (1980) Retinotopic organization of areas 20 and 21 in the cat. J. Comp. Neurol. 193: 147-164.

Wepsic, J. G. (1966) Multimodal sensory activation of cells in the magnocellular medial geniculate nucleus. Exp. Neurol. 15: $299-318$.

Winer, J. A. (1979) Neurons of the medial division of the medial geniculate body of the cat. Anat. Rec. 193: 723.

Winer, J. A. (1984) The anatomical organization of the medial geniculate body of the cat: Cytoarchitecture, neuronal architecture, and cortical connections. Adv. Anat. Embryol. Cell Biol., in press.

Winer, J. A., and D. K. Morest (1978) Morphology of neurons and axons in the dorsal nucleus of the medial geniculate body of the cat: Study with the Golgi method. Soc. Neurosci. Abstr. 4: 12 .

Winer, J. A., and D. K. Morest (1979) What is a homology in the central nervous system? Golgi study of the cat and opossum medial geniculate body. Soc. Neurosci. Abstr. 5: 147.

Winer, J. A., and D. K. Morest (1983a) The neuronal architecture of the dorsal division of the medial geniculate body of the cat. A study with the rapid Golgi method. J. Comp. Neurol., in press.

Winer, J. A., and D. K. Morest (1983b) Axons of the dorsal division of the medial geniculate body of the cat: A study with the rapid Golgi method. J. Comp. Neurol., in press.

Winer, J. A., I. T. Diamond, and D. Raczkowski (1977) Subdivisions of the auditory cortex of the cat: The retrograde transport of horseradish peroxidase to the medial geniculate body and posterior thalamic nuclei. J. Comp. Neurol. 176 : 387-418.

Woolsey, C. N. (1961) Organization of cortical auditory system. In Sensory Communication, W. A. Rosenblith, ed., pp. 235257, MIT Press, Cambridge, MA.

Woolsey, C. N. (1964) Flectrophysiological studies on thalamocortical relations in the auditory system. In Unfinished Tasks in the Behavioral Sciences, A. Abrams, H. H. Garner, and J. E. P. Toman, eds., pp. 45-57, The Williams \& Wilkins Co., Baltimore. 